Review Paper

\title{
Consolidated derivation of fracture mechanics parameters and fatigue theoretical evolution models: basic review
}

\author{
E.S. Ameh ${ }^{1}$
}

Received: 9 July 2019 / Accepted: 22 September 2020 / Published online: 9 October 2020

(c) Springer Nature Switzerland AG 2020

\begin{abstract}
Presence of cracks lead to structural steels failure below critical yield strength. The primary aim of the present article is to simplify and consolidate mathematical derivation of stress concentration, fracture stress, stress intensity factor, crack tip opening displacement and J-integral parameters from the first principle as well as application to fatigue. The review explains the mathematical derivation of fracture mechanics parameters from the theoretical concept, including alternatives to fatigue life prediction with strain-based approach method. The stress concentration around a notch can only be performed if the radius of the notch is far greater than zero and the stress field at sharp crack shows singularity when the crack tip radius is equal to zero. Furthermore, blunted crack tip violates stress singularity, while the crack tip opening displacement and J-integral parameters show the solution of a crack extending beyond zero crack tip radius, thus are used to characterize material stress fields with blunted crack tip. The review highlights benefit of characterizing fatigue crack growth with J-integral and crack tip opening displacement parameters over stress intensity factor. This paper would benefit majorly engineers and specialists in nuclear, aviation, oil and gas industries.
\end{abstract}

Keyword Crack tip opening displacement $\cdot$ Fatigue $\cdot$ J-integral $\cdot$ Plastic zone $\cdot$ Stress intensity factor

$\begin{array}{llll}\text { Abbreviations } & u_{x, y} & \text { Displacement field in X and Y direction } \\ \Delta \mathrm{k} & \text { Applied stress intensity factor } & u_{i} & \text { Displacement vector } \\ \Gamma & \text { Close path } & d s & \text { Displacement along contour } \\ \mathrm{d} v & \text { Change in load displacement } & \Delta \mathrm{k}_{e f f} & \text { Effective stress intensity factor range } \\ n & \text { Constant for deeply notched specimen } & \gamma_{s} & \text { Elastic surface energy } \\ \psi, \chi & \text { Complex analytical function } & \rho^{*} & \text { Elementary material block size } \\ \bar{z} & \text { Conjugate function } & \alpha & \text { Ellipse coordinate lines } \\ a & \text { Crack length } & G & \text { Energy release rate } \\ \Delta a & \text { Change in crack length } & d a / d N & \text { Fatigue crack growth rate } \\ k_{o p} & \text { Crack opening stress factor } & \varepsilon_{f}^{\prime} & \text { Fatigue ductility coefficient } \\ \Delta C T O D & \text { Crack tip opening displacement } & c & \text { Fatigue ductility exponent } \\ k_{c} & \text { Critical fracture toughness of material } & \sigma_{f}^{\prime} & \text { Fatigue strength coefficient } \\ \rho_{c} & \text { Critical dislocation density } & d & \text { Fatigue strength exponent } \\ r & \text { Crack tip radius } & \Phi & \text { General stress function } \\ k^{\prime} & \text { Cyclic strength coefficient } & \beta & \text { Hyperbola coordinate lines } \\ n^{\prime} & \text { Cyclic strain hardening exponent } & d a & \text { Incremental crack length } \\ \rho & \text { Density } & d N & \text { Incremental number of stress cycle } \\ U_{d} & \text { Dislocation strain energy } & (z) & \text { Integral of complex function }\end{array}$

E. S. Ameh, stanley.ameh@yahoo.com | 'Department of Mechanical Engineering, University of Benin, Benin, Edo State, Nigeria. 


\begin{tabular}{|c|c|}
\hline da & Incremental crack length \\
\hline$\Delta J$ & J-integral range \\
\hline$R$ & Stress ratio \\
\hline$V_{\max }$ & Maximum load line displacement \\
\hline$\sigma_{\max }$ & Maximum stress \\
\hline$k_{\max }$ & Maximum stress intensity factor range \\
\hline$\sigma_{m}$ & Mean stress \\
\hline$k_{\text {max }, \text { tot }}$ & Maximum total stress intensity factor range \\
\hline$k_{\min }$ & Minimum stress intensity factor range \\
\hline$V_{\min }$ & Minimum load line displacement \\
\hline$N_{f}$ & $\begin{array}{l}\text { Number of cycles required for representative } \\
\text { material }\end{array}$ \\
\hline$C_{k}, m_{k}$ & $\begin{array}{l}\text { Paris empirical parameters based on stress } \\
\text { intensity factors test data }\end{array}$ \\
\hline$c_{\delta}, m_{\delta}$ & $\begin{array}{l}\text { Paris empirical parameters based on CTOD test } \\
\text { data }\end{array}$ \\
\hline$C_{J}, m_{J}$ & $\begin{array}{l}\text { Paris empirical parameters based on J-integral } \\
\text { test data }\end{array}$ \\
\hline$n_{k}$ & Path surrounding crack tip \\
\hline$r_{\rho}$ & Plastic zone size \\
\hline$\pi$ & Potential energy \\
\hline$B$ & Specimen thickness \\
\hline$k_{r}$ & Residual stress intensity factor \\
\hline$\varepsilon$ & Strain \\
\hline$U^{*}$ & Strained energy per unit volume \\
\hline$U$ & External strained energy in the body \\
\hline W & Work done by external body \\
\hline$\Delta \varepsilon$ & Strain range \\
\hline$\varepsilon_{i j}$ & Strain tensor \\
\hline$\sigma_{r, \theta, z}$ & Stress components in polar coordinate \\
\hline$\sigma_{x x, y y, z z}$ & Stress components in cartesian coordinate \\
\hline$k$ & Stress concentration \\
\hline$\sigma$ & Stress \\
\hline$k_{1}$ & Stress intensity factor \\
\hline$k_{\text {th }}$ & Stress intensity factor threshold \\
\hline$R$ & Stress ratio \\
\hline$\Delta k_{\text {tot }}$ & Total stress intensity factor \\
\hline$T_{i}$ & Traction Vector \\
\hline$n_{j}$ & Unit normal vector \\
\hline$b$ & Uncracked ligament length \\
\hline$W_{s}$ & Work required creating new surface \\
\hline$E$ & Young modulus \\
\hline$\sigma_{y s}$ & Yield strength \\
\hline
\end{tabular}

\section{Introduction}

Fracture mechanics is a set of theories that describe behaviour of structures with geometrical discontinuities, which combine the study of mechanical properties and cracked bodies [1]. The first fracture mechanics theory relating to crack, which is premised upon energy balance was initiated by Griffith [2]. Griffith theory of fracture strength was rarely taken seriously until during and after the World War II, following the catastrophic failures of welded liberty ships, oil storage tanks, gas transmission lines, bridges and pressurized cabin planes [3]. The Griffith theory was later modified by Orowan [4] and Irwin [5] at different times to accommodate plastic flow materials and understand structures' failure causes. Irwin $[3,6]$ further introduced the stress intensity factor and energy release rate to describe fracture behaviour under small scale yielding materials. Subsequently, crack tip opening displacement and J-integral theoretical models were introduced by Wells [7] and Rice [8] respectively to describe fracture behaviour under large scale yielding materials. Cracks have been known to initiate and propagate from geometrical discontinuities such as defects, cut-outs, edges and holes for structures under loading, but the propagation crack size and propagation rate are dependent on discontinuity shape and the type of applied load [9]. Crack presence in a steel has been widely acknowledged to reduce reliability of inservice components and structures $[10,11]$. Thus, the crack under load leads to fatigue crack propagation, eventual reduction of structural reliability, and to failures [11, 12]. Fatigue has been a leading cause of gas turbine engine components of modern military aircrafts, thus increases maintenance cost of military aircrafts $[13,14]$. Prediction of the fatigue crack growth under variable amplitude loading in aircrafts and engineering structures remains a big challenge owing to the loading sequence effect [15]. Integrity assessment of structures, pressure vessels, and piping systems in nuclear, oil and gas industries are necessary because any severe failure may lead to irreparable loss of monetary values and human life [16]. Consequently, the crack and fracture remained a problem for all man-made metallic components in fracture mechanics communities [16]. Therefore, clearer understanding and incorporation of fracture mechanics into design, prediction and integrity assessment approaches could reduce failure rates and maintenance of engineering materials.

The fracture behavior of materials is classified into brittle and ductile fractures. The brittle fracture occurs in materials that exhibit little or no plastic deformation and the fracture mechanism is transgranular because it occurs along well-defined crystallographic planes within each grain. But the ductile fracture occurs in materials that show high plastic deformation failure and the fracture mechanism is associated with void nucleation and growth that occurs along grain boundaries [17]. Most structural steels' failures occur because of the presence of cracks that were either inherited during manufacturing, installation or in-service depending on design and condition of service. Cracks under critical loads are preceded with crack growth, reduction in structural strength and final failure of the materials depending on the critical 
fracture toughness of the structural steels [18]. Fracture mechanics was later categorized into linear elastic and elastic-plastic fracture mechanics based on the degree of plastic deformation at the tip of a crack. The study of fracture mechanics took a different dimension following the unprecedented structural failures after the World II, leading to several mathematical models to characterize and quantify fracture toughness [19]. Zhu and Joyce [20] gave a technical review of linear elastic and elastic-plastic fracture mechanics parameters. Historic development of fracture parameters was presented by Erdogan [21] and Cottrell [22]. Shinde and Dhamejani [23] provided a review of early investigations and advances in energy release rate, J-integral, and crack tip opening displacement. Elices et al. [24] reviewed advantages, challenges and limitations of cohesive zone modeling. The authors concluded that cohesive modeling showed good prediction of metallic, glassy, and composite's notched samples. Kumar et al. [25] and Beden et al. [26] gave an overview of fatigue crack growth models by Walker, Brock, Priddle, McEvily, Foreman, Collipriest, Zheng, Wang and several others. The authors gave detailed contributions and improvements made by each model. The technical reviews presented until now are limited to only survey and have not considered mathematical derivation of the basic fracture parameters from first principle and fatigue applications. Therefore, the present article provides detailed and simplified derivation of fracture mechanics parameters and the theoretical evolution models from the first principle to improve and understand the derivations and subsequent analytical application to structural integrity management.

Section 2 of this paper present basic review of mathematical derivation of linear-elastic fracture mechanics parameters, namely stress concentration, fracture stress, and stress intensity factor. Detailed review of mathematical derivation of elastic-plastic fracture mechanics parameters such as crack tip opening displacement and J-integral were outline in Sect. 3 of the paper. While Sect. 4 of the paper presents comparative description, benefits and applications of fatigue growth based on small scale plasticity, large scale plasticity and local strain approaches.

\section{Linear elastic fracture mechanics}

Scientific knowledge of linear elastic fracture mechanics is based on the theory that energy dissipation is correlated to the fracture process and the deformation is linearly elastic. Analytically, the stress field at a crack tip is correlated to normal stress, orientation, crack size and shape of the crack [27]. The applications of linear elastic fracture mechanics are valid only if the plastic deformation at the crack tip remains insignificant to the geometry and crack lengths. Therefore, the applications are limited to brittle fracture materials by assuming linear elastic stress-strain behavior of materials. However, it may be applied to a structure with a large crack but when the crack length becomes comparable with one of the material geometries scales, linear elastic fracture mechanics becomes invalid and predicted strength becomes infinite when the crack length tends to zero [28]. The linear elastic fracture mechanics theoretical evolution models include stress concentration, fracture stress and stress intensity factor.

\subsection{Stress concentration}

Inglis [29] employed mathematical theory to extend Kirsch's work by formulating theoretical stress field at the vicinity of a flat plate containing an elliptical hole under constant loading as shown in Fig. 1.The minor and principal axes are represented with $2 \mathrm{~b}$ and $2 \mathrm{a}$ respectively to determine stress concentration. Thereafter, Neuber [30] developed theoretical model that allowed computation of maximum stress at the edge of elliptical hole in a flat plate under the same loading condition. But the stress distribution at the edge of the infinite plate with elliptical hole under biaxial loading was studied by Durelli and Murray [31].

Complex potential functions were employed and related to Airy stress function [32]:

$$
\begin{gathered}
\sigma_{x x}=\frac{\partial^{2} \Phi}{\partial x^{2}} \\
\sigma_{y y}=\frac{\partial^{2} \Phi}{\partial y^{2}}
\end{gathered}
$$

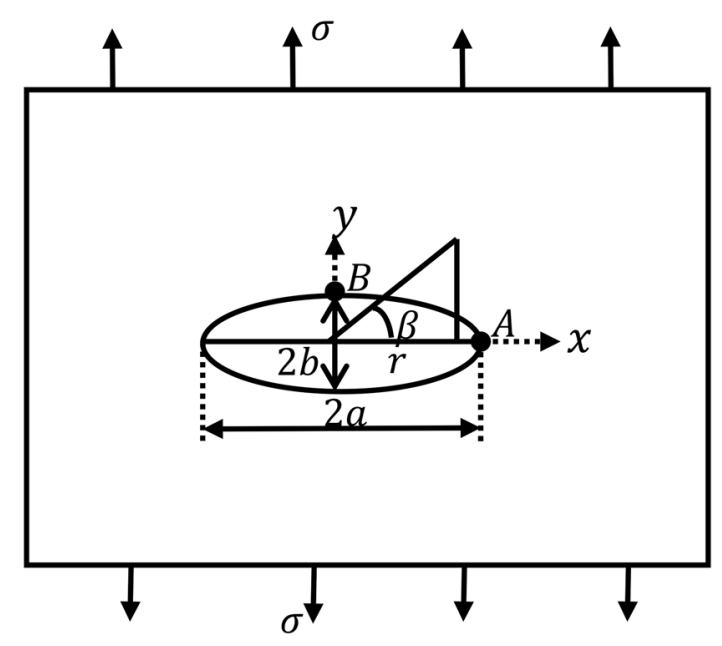

Fig. 1 Elliptical hole in a flat plate 
$\sigma_{x y}=\frac{\partial^{2} \Phi}{\partial x \partial y}$

Assuming a general stress function $\Phi$ from any two analytical functions $\psi$ and $\chi$ could be stated as:

$\Phi=\operatorname{Re}[(x-i y) \psi(z)+\chi(z)]$

or

$\Phi=\operatorname{Re}[\bar{z} \psi(z)+\chi(z)]$

Note that conjugation function $\bar{z}=x-i y$, and analytical function $f(z)=\alpha+i \beta$ or $x+i y$.

Substituting Eq. (5) into Eqs. $(1,2)$ gives:

$\sigma_{x x}+\sigma_{y y}=4 \operatorname{Re}\left[\psi^{\prime}(z)\right]=2\left[\psi^{\prime}(z)+\bar{\psi}^{\prime}(z)\right]$

$\sigma_{y y}-\sigma_{x x}+2 i \sigma_{x y}=2\left[\bar{z} \psi^{\prime \prime}(z)+\chi^{\prime \prime}(z)\right]$

The primes indicate differentiation with respect to $z$ and the overbars indicate conjugate function. The component stresses are given as:

$\sigma_{\alpha \alpha}+\sigma_{\beta \beta}=4 \operatorname{Re}\left[\psi^{\prime}(z)\right]$

$-\sigma_{\alpha \alpha}+\sigma_{\beta \beta}+2 i \sigma_{\alpha \beta}=2\left[\bar{z} \psi^{\prime \prime}(z)+\chi^{\prime \prime}(z)\right] e^{2 i \theta}$

The coordinates of the elliptical hole may be written in the complex variable form as:

$z=c \cosh \varsigma, \quad \varsigma=\alpha+i \beta$

For elliptical hole analysis, the $\beta$ varies from 0 to $2 \pi$ while $\alpha$ never changes at $\alpha_{o}$ in moving round the boundary of ellipse. Hence, the stresses are periodic in $\beta$, with $2 \pi$ equaling the uniaxial stress components, $\sigma_{y y}=\sigma, \sigma_{x x}=\tau_{x y}=0$. But the elliptical boundary conditions may be satisfied by potential functions in the forms:

$4 \psi(z)=A c \cosh \varsigma+B c \sinh \varsigma$

$4 \chi(z)=C c^{2} \varsigma+D c^{2} \cosh 2 \varsigma+E c^{2} \sinh 2 \varsigma$

where the constants $A, B, C, D$ and $E$ are estimated from the given boundary conditions. The complex potentials after the boundary conditions are given as:

$4 \psi(z)=\sigma c\left[\left(1+e^{2 \alpha_{o}}\right) \sinh 2 \varsigma-e^{2 \alpha_{o}} \cosh 2 \varsigma\right]$
The sum of stress components $\sigma_{\alpha}$ and $\sigma_{\beta}$ at the edge of the elliptical hole at point $A$ is expressed as:

$\left(\sigma_{\alpha}+\sigma_{\beta}\right) \alpha_{o}=\sigma \frac{\sinh 2 \alpha_{o}-1+e^{2 \alpha_{o}} \cos 2 \beta}{\cosh 2 \alpha_{o}-\cos 2 \beta}$

Equation (15) employed the law of tangents which takes the form: $\frac{a+b}{a+b}=\frac{\tan 1 / 2^{(\alpha+\beta)}}{\tan 1 / 2^{(\alpha-\beta)}}$.

The component stress $\sigma_{\alpha}=0$ at the edge of the hole $\left(\alpha=\alpha_{o}\right)$, hence Eq. (15) is further reduced to:

$\left(\sigma_{\beta}\right) \alpha_{o}=\sigma \frac{\sinh 2 \alpha_{o}-1+e^{2 \alpha_{o}} \cos 2 \beta}{\cosh 2 \alpha_{o}-\cos 2 \beta}$

The maximum component stress $\left(\sigma_{\beta}\right) \alpha_{o}$ occurs when $\beta=0, \pi$. Hence Eq. (16) is reduced to:

$\left(\sigma_{\beta}\right) \alpha_{o, \beta=0}=\sigma \frac{\sinh 2 \alpha_{o}-1+e^{2 \alpha_{o}}}{\cosh 2 \alpha_{o}-1}=\sigma\left(1+2 \operatorname{coth} \alpha_{o}\right)=\sigma\left(1+\frac{2 a}{b}\right)$

$\gg \sigma_{\text {max }}=\sigma_{\text {nom }}\left(1+\frac{2 a}{b}\right) k=\frac{\sigma_{\text {max }}}{\sigma_{\text {nom }}}=\left(1+\frac{2 a}{b}\right)$

Stress concentration, $k$ defined as $k=\frac{\sigma_{\max }}{\sigma_{\text {nom }}}$ is computed with Eq. (17). But for sharp cracks, where $a \gg \rho$, Eq. (17) is further reduced to:

$a \gg \rho, \sigma_{\max }=2 \sigma \frac{a}{\rho}$.

\subsection{Fracture stress}

According to Rossmanith [33], Karl Weighardt (1874-1924) was the first to solve exact solution of a real crack tip field problem under a single force at a crack face but realized that failure of a real crack problem cannot be solved with traditional failure criteria. Griffith [2] extended Inglis stress analysis by introducing crack in a material and investigating whether existing crack in a material would grow under loading and concluded fracture stress of the material was far lower than predicted theoretical strength in the presence of crack. The analysis considered a linear elastic material with crack length $a$ and thickness $B$ as shown in Fig. 2 by employing energy balance approach instead of crack tip stress directly.

Strained energy per unit volume of the material under stress is:

$U^{*}=\frac{1}{V} \int d x=\int \frac{F}{A} \frac{d x}{L}=\int \sigma d \varepsilon$

$4 \chi(z)=-\sigma c^{2}\left[\left(\cosh 2 \alpha_{o}-\cosh \pi\right) \varsigma+\frac{1}{2} e^{2 \alpha_{o}}-\cosh 2 \varsigma\left(\varsigma-\alpha_{o}-\frac{i \pi}{2}\right)\right]$ 
Fig. 2 a Crack under remote stress. b Fracture energy balances

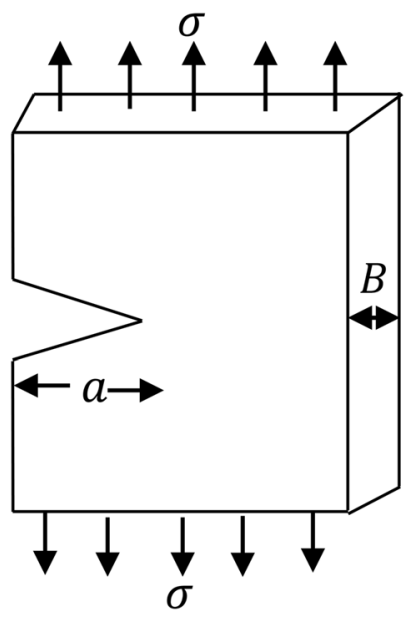

(a)

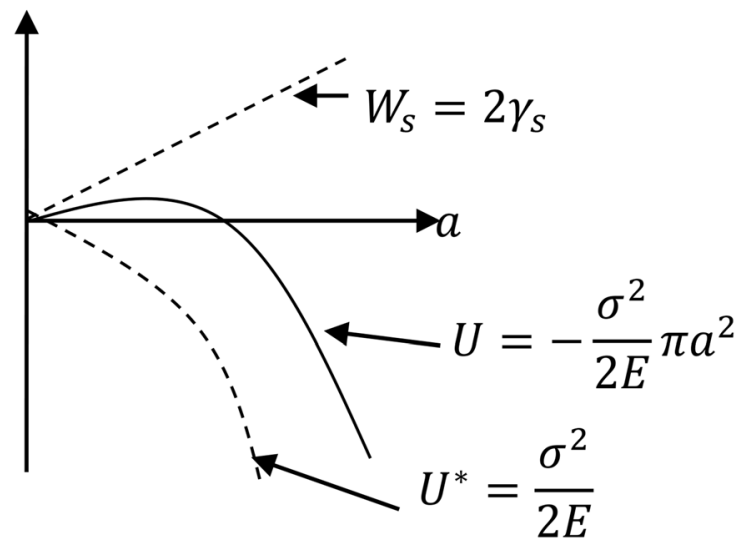

(b)
For a linear material, $\sigma=E \varepsilon$. Therefore, strained energy per unit volume of the material under stress is:

$U^{*}=\frac{E \varepsilon^{2}}{2}=\frac{\sigma^{2}}{2 E}$

Assuming the total external strained energy $U$ released was strained energy per unit volume times the volume in both triangular regions as:

$U=\frac{\sigma^{2}}{2 E} \pi a^{2}$

The elastic surface energy $\gamma_{s}$ related to length of crack $a$ is given as:

$W_{s}=2 \gamma_{s} a$

where $\gamma=$ surface energy which has $\mathrm{J} / \mathrm{m}^{2}$ as unit. Using the energy balance approach fracture criteria for an increase in crack area $d A$ is:

$W=U+W_{s}$

$$
\text { or } \frac{\partial W}{\partial A}-\frac{\partial U}{\partial A}=\frac{\partial W_{s}}{\partial A}
$$

and, $\quad-\pi=W_{s}$

$$
\text { or }-\frac{\partial \pi}{\partial A}=\frac{\partial W_{s}}{\partial A} \text {. }
$$

Equation (23) can further be written as:

$-\frac{\partial \pi}{\partial A}=\frac{\partial W}{\partial A}-\frac{\partial U}{\partial A}=\frac{\partial W_{s}}{\partial A}$

where $\pi=$ energy potential provided by the internal strained energy and forces, $W=$ work done by external body, $U=$ external strained energy in the body, $A=$ area of the crack surface and $W_{s}=$ work required to create new surface. Griffith finally formulated Eq. (26) using Inglis stress analysis by equating: $-U=W_{s}$, if $W=0$ for potential energy of uncracked body:

$\frac{\partial U}{\partial A}=\frac{\partial W_{s}}{\partial A}$

$\frac{\sigma^{2} \pi a^{2}}{2 E}=2 \gamma_{s}$

$\sigma_{f=} \sqrt{\frac{2 E \gamma_{s}}{\pi a}}$

Fracture stress, $\sigma_{f}$ occur when Griffith Eq. (26) is satisfied.

\subsection{Stress intensity factor}

Westergaard [34] developed solution of a crack problem by considering a center crack in an infinite plate in a complex polar coordinate shown in Fig. 3.

Westergaard proposed the complex function of the form:

$F(z)=\operatorname{Re} \overline{\bar{z}}(z)+y \operatorname{lm} \bar{z}(z)$

where $F(z)$ is analytical stress function, $\overline{\bar{z}}$ and $\bar{z}$ are second and first integral of complex function ( $z)$. The function $\bar{z}, \bar{z}, z$ and $z^{\prime}$ are defined as:

$\bar{z}=\frac{d \overline{\bar{z}}}{d z}, z=\frac{d \bar{z}}{d z}, z^{\prime}=\frac{d z}{d z}$

Applying the Cauchy-Riemann condition, and taking the first derivative of $F(z)$ with respect to $y$ :

$\frac{\partial F}{\partial y}=\frac{\partial R e \overline{\bar{z}}}{\partial y}+y \frac{\partial \operatorname{Im} \bar{z}}{\partial y}+\operatorname{Im} \bar{z} \frac{\partial y}{\partial y}=\frac{\partial \operatorname{Re} \overline{\bar{z}}}{\partial y}+y \frac{\partial \operatorname{Im} \bar{z}}{\partial y}+\operatorname{Im} \bar{z}$ 


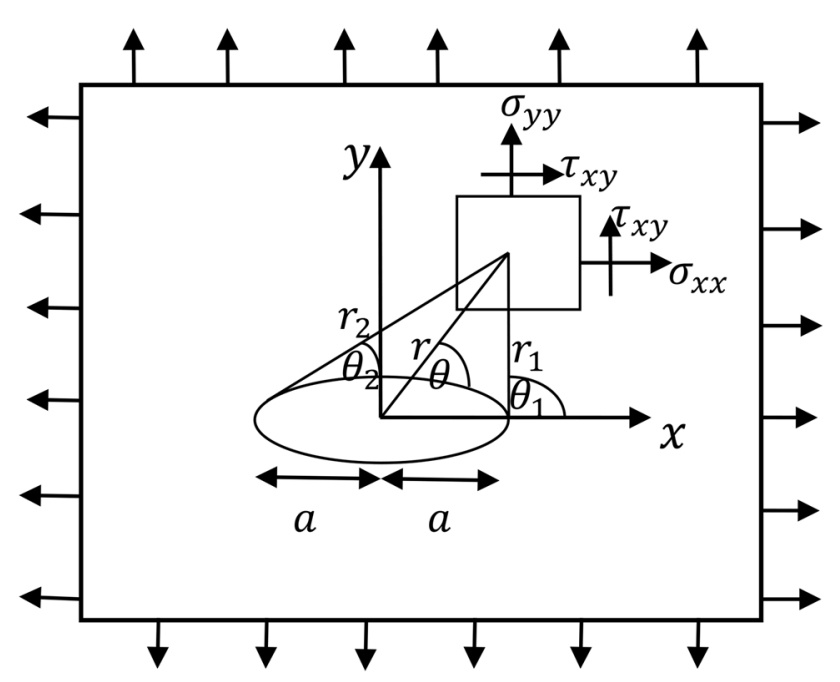

Fig. 3 An infinite plate with circular hole

Using the Cauchy-Riemann relation, Eq. (28) is further reduced to

$\frac{\partial F}{\partial y}=-I m \bar{z}+y \operatorname{Rez}+I m \bar{z}=y \operatorname{Rez}$

Differentiating Eq. (29) further and substituting into Eqs. (1-3), Airy stress function yield the following:

$\sigma_{x x}=\frac{\partial^{2} F}{\partial y^{2}}=\frac{\partial(y \operatorname{Rez})}{\partial y}=y \frac{\partial \operatorname{Rez}}{\partial y}+\operatorname{Rez} \frac{\partial y}{\partial y}=\operatorname{Rez}-y I m z^{\prime}$

$\sigma_{y y}=\frac{\partial^{2} F}{\partial x^{2}}=\partial^{2}(\operatorname{Re} \overline{\bar{z}}+y I m \bar{z})=\operatorname{Rez}+y I m z^{\prime}$

$\tau_{x y}=\frac{\partial^{2} F}{\partial x \partial y}=-\frac{\partial(\partial F / \partial y)}{\partial x}=-\frac{\partial(y R e z)}{\partial x}=-y R e z^{\prime}$

The Eq. (30) can be further compared with Eq. (31):

$$
\begin{aligned}
& \sigma_{x x}=\Phi+y \frac{\partial \Phi}{\partial y} \\
& \sigma_{y y}=\Phi-y \frac{\partial \Phi}{\partial x} \\
& \tau_{x y}=-y \frac{\partial \Phi}{\partial x}
\end{aligned}
$$

In the same vein, mode II is given as:

$\begin{aligned} \sigma_{x x} & =2 R e z-y I m z^{\prime} \\ \sigma_{y y} & =y I m z^{\prime} \\ \tau_{x y} & =-I m z-y R e z^{\prime}\end{aligned}$

Muskhelishvili [35] denoted the complex variable $z$ as in Eq. (33) and complex function $z(z)$ as in Eq. (34):

$$
\begin{aligned}
& z-a=(x-a)+i y=r_{1} e^{i \theta_{1}}=r_{1}\left(\cos \theta_{1}+i \sin \theta_{2}\right) \\
& z+a=(x+a)+i y=r_{2} e^{i \theta_{2}}=r_{2}\left(\cos \theta_{2}+i \sin \theta_{2}\right) \\
& z(z)=\frac{z \sigma}{\sqrt{z^{2}-a^{2}}} \text { and } z^{\prime}=0 \\
& \bar{z}=\sigma\left(z^{2}-a^{2}\right)^{1 / 2} \\
& z=\frac{d \bar{z}}{d z}=\sigma / 2\left(z^{2}-a^{2}\right)^{-1 / 2} * 2 z=\sigma z\left(z^{2}-a^{2}\right)^{-1 / 2} \\
& z^{\prime}=\sigma\left\{-z^{2}\left(z^{2}-a^{2}\right)^{-3 / 2}+\left(z^{2}-a^{2}\right)^{-1 / 2}\right\}
\end{aligned}
$$

Substituting either Eqs. (33) or (35-37) into (32) yield the following stresses in the center crack.

$$
\begin{aligned}
\sigma_{x x} & =\frac{\sigma r}{\sqrt{r_{1} r_{2}}} \cos \left(\theta-\frac{\theta_{1}+\theta_{2}}{2}\right)-\frac{\sigma a^{2}}{\left(r_{1} r_{2}\right)^{3 / 2}} r_{1} \sin \theta_{1} \sin \frac{3}{2}\left(\theta_{1}+\theta_{2}\right) \\
\sigma_{y y} & =\frac{\sigma r}{\sqrt{r_{1} r_{2}}} \cos \left(\theta-\frac{\theta_{1}+\theta_{2}}{2}\right)+\frac{\sigma a^{2}}{\left(r_{1} r_{2}\right)^{3 / 2}} r_{1} \sin \theta_{1} \sin \frac{3}{2}\left(\theta_{1}+\theta_{2}\right) \\
\tau_{x y} & =\frac{\sigma a^{2}}{\left(r_{1} r_{2}\right)^{3 / 2}} r_{1} \sin \theta_{1} \cos \frac{3}{2}\left(\theta_{1}+\theta_{2}\right)
\end{aligned}
$$

From Fig. 3, the following assumptions can be made if a chosen line lies close to one of the crack tips on the right-hand side.

$r_{2}=2 a, r=a$ and $\theta_{2}=\theta=0$

Substituting Eqs. (39) into Eq. (38) yield stresses in the immediate vicinity of the crack tips as:

$\sigma_{x x}=\frac{\sigma \sqrt{\pi a}}{\sqrt{2 \pi r_{1}}} \cos (\theta / 2)[1-\sin (\theta / 2) \sin (3 \theta / 2)]+\cdots$

$\sigma_{y y}=\frac{\sigma \sqrt{\pi a}}{\sqrt{2 \pi r_{1}}} \cos (\theta / 2)[1+\sin (\theta / 2) \sin (3 \theta / 2)]+\cdots$

$\tau_{x y}=\frac{\sigma \sqrt{\pi a}}{\sqrt{2 \pi r_{1}}} \cos (\theta / 2) \sin (\theta / 2) \cos (3 \theta / 2)+\cdots$

Irwin $[6,36]$ formulated theory of stress intensity factor using Westergaard solution approach as indicated in Fig. 4. Irwin showed stresses and displacements close to linear elastic material with a crack tip could be computed with a single governing parameter, called stress intensity factor. The theory showed elastic stress fields nearby a crack tip are presumably identical and the stress intensity factor $(k)$ is proportional to the stress times the crack length square root $(k \propto \sigma \sqrt{\pi r})$. Therefore, for any given 


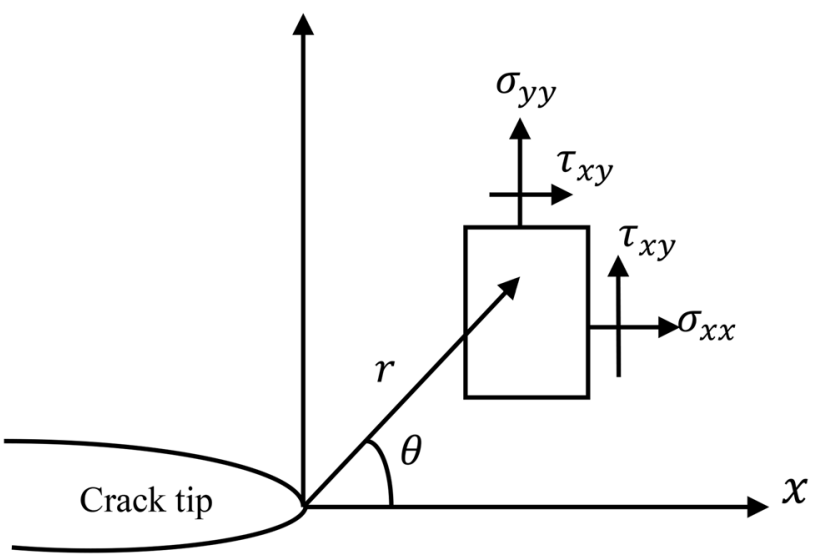

Fig. 4 Stresses at crack tip of a crack

geometry and loading, the term $\sqrt{\pi a}$ is a constant and can be replaced with constant $k$. Stress fields around the tip of a crack were categorized into three deformation modes namely mode I (tensile), mode II (shearing) and mode III (tearing).

The asymptotic displacements and stress fields at the tip of a crack for material subjected to any of the three modes of crack propagation are given as:

For model / crack tip deformation, the stress fields are given as:

$\sigma_{x x}=\frac{k_{l}}{\sqrt{2 \pi r_{1}}} \cos (\theta / 2)[1-\sin (\theta / 2) \sin (3 \theta / 2)]$

$\sigma_{y y}=\frac{k_{l}}{\sqrt{2 \pi r_{1}}} \cos (\theta / 2)[1+\sin (\theta / 2) \sin (3 \theta / 2)]$

$\tau_{x y}=\frac{k_{l}}{\sqrt{2 \pi r_{1}}} \sin (\theta / 2) \cos (\theta / 2) \cos (3 \theta / 2)$

$\sigma_{z z}=v\left(\sigma_{x}+\sigma_{y}\right), \tau_{x z}=\tau_{y z}=0$

For plane strain, $\sigma_{z z}=0$ while plane stress, $\sigma_{y y}=\lim _{r \rightarrow 0} \frac{k_{1}}{\sqrt{2 \pi r}}$

$$
\theta=0
$$

For mode II,

$\sigma_{x x}=\frac{k_{l l}}{\sqrt{2 \pi r_{1}}} \sin (\theta / 2)[2+\cos (\theta / 2) \cos (3 \theta / 2)]$

$\sigma_{y y}=\frac{k_{l l}}{\sqrt{2 \pi r_{1}}} \sin (\theta / 2) \cos (\theta / 2) \cos (3 \theta / 2)$

$\tau_{x y}=\frac{k_{\|}}{\sqrt{2 \pi r_{1}}} \cos (\theta / 2)[1-\sin (\theta / 2) \sin (3 \theta / 2)]$

$\sigma_{z z}=v\left(\sigma_{x}+\sigma_{y}\right), \tau_{x z}=\tau_{y z}=0$

Plane strain $\sigma_{z z}=0$, for plane stress

$$
\tau_{x y}=\lim _{\substack{r \rightarrow 0 \\ \theta=0}} \frac{k_{\|}}{\sqrt{2 \pi r}}
$$

For mode III,

$$
\begin{aligned}
\sigma_{x x} & =\sigma_{y y}=\sigma_{z z}=\tau_{y z}=0 \\
\tau_{x z} & =\frac{k_{I I I}}{\sqrt{2 \pi r_{1}}} \\
\tau_{y z} & =\frac{k_{I I I}}{\sqrt{2 \pi r_{1}}} \cos (\theta / 2)
\end{aligned}
$$

Polar stress components can be expressed in terms of Cartesian stress components as given in Eq. (44):

$\sigma_{r r}=\sigma_{x x} \cos ^{2} \theta+\sigma_{y y} \sin ^{2} \theta+\tau_{x y} \sin 2 \theta$

$\sigma_{\theta \theta}=\sigma_{x x} \sin ^{2} \theta+\sigma_{y y} \cos ^{2} \theta-\tau_{x y} \sin 2 \theta$

$\tau_{r \theta}=\sin \theta \cos \theta\left(\sigma_{y y}-\sigma_{x x}\right)+\tau_{x y} \cos 2 \theta$

Using Eq. (44), mode I and /l equations can be represented in a polar coordinate form $\sigma_{r r}, \sigma_{\theta \theta}$ and $\tau_{r \theta}$ as follow:

Mode I

$\sigma_{r r}=\frac{k_{l}}{\sqrt{2 \pi r_{1}}} \cos (\theta / 2)\left[1+\sin ^{2}(\theta / 2)\right]$

$\sigma_{\theta \theta}=\frac{k_{l}}{\sqrt{2 \pi r_{1}}} \cos (\theta / 2)\left[1-\sin ^{2}(\theta / 2)\right]$

$\tau_{r \theta}=\frac{k_{l}}{\sqrt{2 \pi r_{1}}} \sin (\theta / 2) \cos ^{2}(\theta / 2)$

$\sigma_{z z}=v\left(\sigma_{x}+\sigma_{y}\right)$. For plane strain

$\sigma_{z z}=0$ and for plane stress,

$\tau_{z \theta}=\tau_{r z}=0$

Mode II

$\sigma_{r r}=\frac{k_{l l}}{\sqrt{2 \pi r_{1}}}[-5 / 4 \sin (\theta / 2)+3 / 4 \sin (3 \theta / 2)]$

$\sigma_{\theta \theta}=\frac{k_{l}}{\sqrt{2 \pi r_{1}}}[-3 / 4 \sin (\theta / 2)-3 / 4 \sin (3 \theta / 2)]$

$\tau_{r \theta}=\frac{k_{l}}{\sqrt{2 \pi r_{1}}}[1 / 4 \sin (\theta / 2)+3 / 4 \sin (3 \theta / 2)]$

$\sigma_{z z}=v\left(\sigma_{r}+\sigma_{\theta}\right)$. For plane strain, $\sigma_{z z}=0$ and for plane stress,

$\tau_{z \theta}=\tau_{r z}=0$ 


\section{Elastic-plastic fracture mechanics}

Elastic-plastic fracture mechanics evaluates stress fields of materials with blunted crack problems that have deformed plastically above the yield stress and exhibited plasticity leading to a plastic zone surrounding the crack tip. This is contrary to linear elastic fracture mechanics which only describes infinite stress at the sharp crack tip and limited to the solution of crack with zero crack tip radius [37]. The study of the plastic zone at the vicinity of the crack tip in hardened materials by McClintock and Irwin [38] and Rice [8] laid the foundation for two basic parameters, crack tip opening displacement (CTOD) and J-integral for characterizing fracture behavior of materials that undergo elastic plastic deformation.

\subsection{Plastic zone model}

Irwin [39] formulated the first and second order approximation of a plastic zone size ahead of crack for mode I as illustrated in Fig. 5 by assuming elastic plastic material.

From Eq. (41), the stress field along $x$-axis at $\theta=0$, yield:

$\sigma_{y y}=\frac{k_{l}}{\sqrt{2 \pi r_{1}}}$

For the first approximation, Irwin assumed a boundary between elastic and plastic behavior occurs when the stress $\sigma_{y y}$ equal a yield strength $\sigma_{y s}$.

$\sigma_{y y}=\sigma_{y s}$

By substituting Eq. (48) into (47), $r$ which is the distance over which plastic deformation occur ahead of the crack tip equals: $r_{\rho}=\frac{1}{2 \pi}\left(\frac{k_{1}}{\sigma_{y s}}\right)^{2}$

Assuming the loads carried by elastic stress distribution is the same before and after plastic yielding:

$\sigma_{y s}\left(r+r_{\rho}\right)=\int_{0}^{r} \sigma_{y} d r=\int_{0}^{r} \frac{k_{1}}{\sqrt{2 \pi r}} d r$

$\gg r_{\rho}=\frac{1}{\pi}\left(\frac{k_{l}}{\sigma_{y s}}\right)^{2} \quad$ Plane stress

Similarly, $r_{\rho}=\frac{1}{\pi}\left(\frac{k_{l l}}{\tau_{y s}}\right)^{2}$

Irwin's conclusion implies that $r+r_{\rho}=2 r_{\rho}$ of the first approximation and that effective yield stress in plane strain is three times of that in plane stress, hence

$r_{\rho}=\frac{1}{3 \pi}\left(\frac{k_{l}}{\sigma_{y s}}\right)^{2} \propto$ Plane stress

Dugdale [40] originally proposed strip yield modelling of plastic zone size ahead of crack tip. However, Barenblatt [41] estimated the effect of plastic strip on stress distribution at the crack tip vicinity in mode I loading, using a strip yield model and then replaced the internal stress distributed on the plastic zone boundary (Fig. 6) with internal tensile stress.

Assuming the actual crack length $2 a$ to be modeled as $2 a+2 \rho$ (Fig. 6) and then established the equilibrium condition as:

$k_{\sigma}+k_{\rho}=0 \gg k_{\sigma}=-k_{\rho}$

The stress intensity factor of a crack with an internal tensile stress $P$ (Fig. 6 c) distributed across its length equals:
Fig. 5 a 1st approximation of plastic zone size for plane stress condition. $\mathbf{b}$ 2nd approximation of plastic zone size

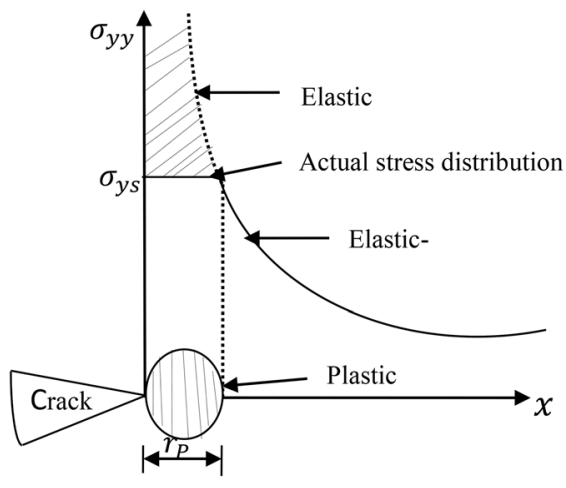

(a)

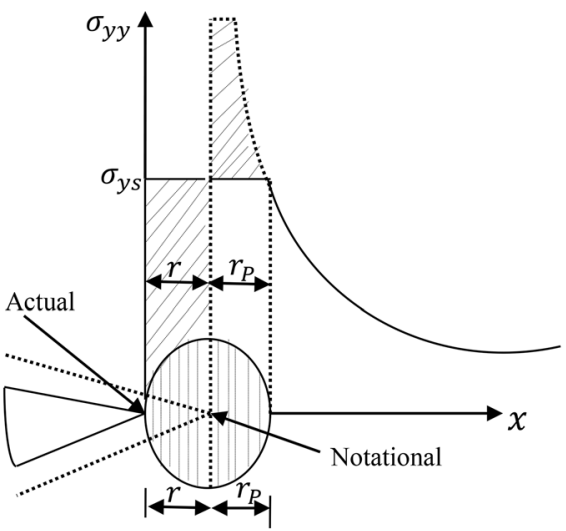

(b) 


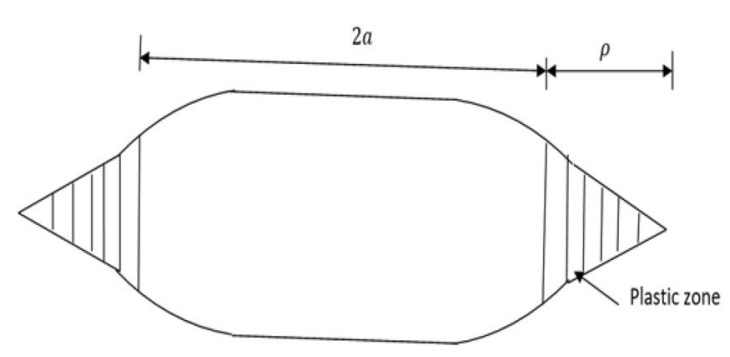

(a)

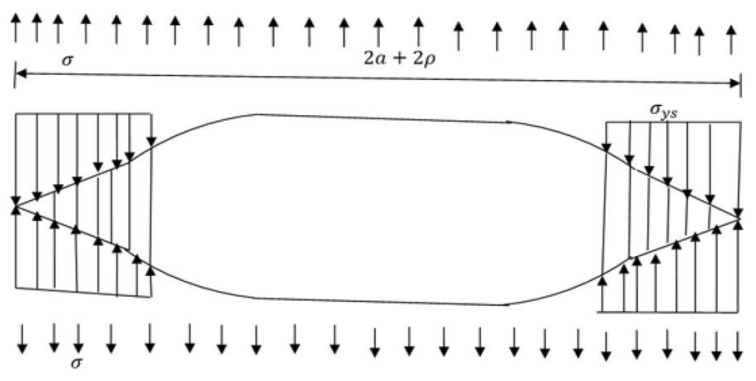

(b)

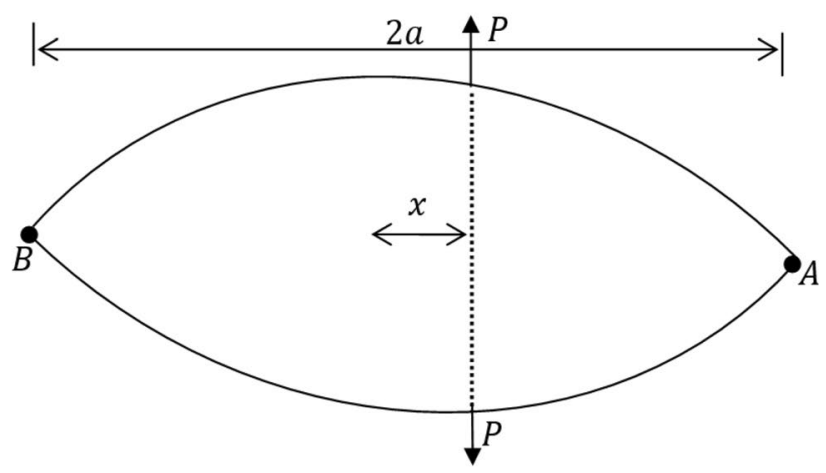

(c)

Fig. 6 a Strip yield plastic zone size. b Plastic zone with closure stress in strip yield. c Dugdale wedge force

$k_{l}=P \sqrt{\pi a}$

General solution for an eccentrical point force may be described by Green's function as:

$k_{I A}=\frac{P}{\sqrt{\pi a}} \sqrt{\frac{a+x}{a-x}}$

$k_{l B}=\frac{P}{\sqrt{\pi a}} \sqrt{\frac{a-x}{a+x}}$

where $k_{I A}=$ stress intensity factor for crack tip $\mathrm{A}, k_{I B}=$ stress intensity factor for crack tip $B$. With a uniformly applied internal pressure $P$ acting as evenly distributed crack opening from the surface to the crack tip, $k$ would be determined by integration of the crack.

$$
\begin{aligned}
& k=\int_{s}^{a}\left(k_{l A}+k_{l B}\right) d x=\int_{s}^{a} \frac{P}{\sqrt{\pi a}}\left[\sqrt{\frac{a+x}{a-x}}+\sqrt{\frac{a-x}{a+x}}\right] d x \\
& \gg k=2 P \frac{\sqrt{a}}{\sqrt{\pi}} \int_{s}^{a} \frac{d x}{\sqrt{a^{2}-x^{2}}}
\end{aligned}
$$

The integration was carried out by a change of variable, $x=a \cos$ which lead to:

$k=2 P \frac{\sqrt{a}}{\sqrt{\pi}} \cos ^{-1}(x / a) \int_{s}^{a}=P \sqrt{\pi} a$

Applying Dugdale crack to Eq. (58) and substituting $a=a+\rho, s=a$ for the integral and $P=-\sigma_{y s}$ gives:

$k_{\rho}=-2 \sigma_{y s} \frac{\sqrt{a+\rho}}{\sqrt{\pi}} \cos ^{-1}(x / a) \int_{a}^{a+\rho}$

$\gg k_{\rho}=-2 \sigma_{y s} \frac{\sqrt{a+\rho}}{\sqrt{\pi}} \cos ^{-1}[a /(a+\rho)]$

From Fig. 5b, stress intensity from tensile stress is given as:

$k_{\sigma}=\sigma \sqrt{\pi(a+\rho)}$

Substituting Eqs. (59) and (60) into Eq. (54) yield:

$\frac{a}{a+\rho}=\cos \left[\frac{\pi a}{2 \sigma_{y s}}\right]$

Dugdale model was expressed to further reduce Eq. (61) using Taylor series: 
$\frac{a}{a+\rho}=1-\frac{1}{2 !}\left(\frac{\pi \sigma}{2 \sigma_{y s}}\right)^{2}+\frac{1}{4 !}\left(\frac{\pi \sigma}{2 \sigma_{y s}}\right)^{4}-\frac{1}{6 !}\left(\frac{\pi \sigma}{2 \sigma_{y s}}\right)^{6}+\cdots$

Neglecting higher order terms and taking the first two terms for cosine gives the plastic zone size:

$\rho=\frac{\pi^{2} \sigma^{2} a}{8 \sigma_{y s}^{2}}=\frac{\pi k^{2}}{2 \sigma_{y s}^{2}}$

\subsection{Crack tip opening displacement}

Wells [7] tried to measure critical stress intensity values of some structural steels and discovered the steels exhibited higher degree of plastic deformation prior to fracture. Thus, crack face movement is proportional to fracture toughness as shown in Fig. 7. Wells concluded stress intensity factor parameter could not be used for blunted crack tip material and suggested crack opening displacement now known as crack tip opening displacement (CTOD) as measuring parameter for the fracture toughness.

McClintock and Irwin [38] showed computation of crack tip opening displacement in relation to crack face displacement from the first principle using Westergaard crack analysis. Using two complex functions $\phi$ and $\psi$ to represent the displacement fields for plane elasticity in mode l:

$4 \mu u_{x}=\operatorname{Re}\left[k \phi-\bar{z} \phi^{\prime}-\psi^{\prime}\right]$

$4 \mu u_{y}=\operatorname{Im}\left[k \phi+\bar{z} \phi^{\prime}+\psi^{\prime}\right]$

where shear modulus $\mu=E / 2(1+v)$ and the constant $k$ is:

$k=3-4 v \quad$ plane strain

$k=3-v / 1+v \quad$ plane stress

Equations (64) and (65) were simplified further with Westergaard approach by setting $\psi^{\prime}=-z \phi^{\prime}+\phi+$ constant while the displacements fields are:

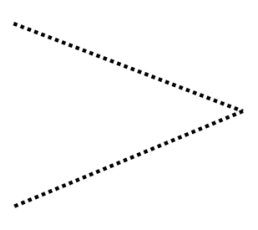

(a)

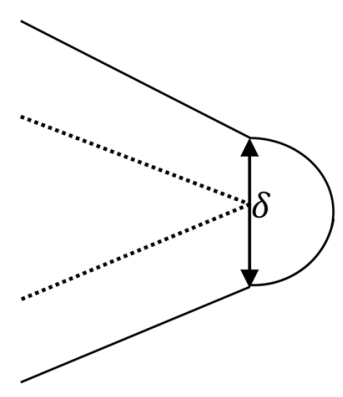

(b)
$2 \mu u_{x}=\frac{k-1}{2} \operatorname{Re} \phi-y \operatorname{lm} \phi^{\prime}$

$2 \mu u_{y}=\frac{k+1}{2} I m \phi-y \operatorname{Re} \phi^{\prime}$

$\phi^{\prime}=\frac{k_{l}}{\sqrt{2 \pi}} \frac{1}{\sqrt{z-a}}$

where $z-a=r e^{i \theta}$, hence $\frac{1}{\sqrt{z-a}}=\frac{1}{\sqrt{(r)} e^{-i \theta / 2}}=$ $1 / \sqrt{r}(\cos \theta / 2-i \sin \theta / 2)$ and

$\phi=\frac{k_{l}}{\sqrt{2 \pi}} 2 \sqrt{z-a}=k_{l} \sqrt{\frac{2}{\pi}} \sqrt{(r)} e^{i \theta / 2}$

Substituting Eqs. (69) and (70) into Eqs. (67) and (68) yield:

$u_{x}=\frac{k_{l}}{2 \mu} \sqrt{\frac{r}{\pi}} \cos \theta / 2\left(k-1+2 \sin ^{2} \theta / 2\right)$

$u_{y}=\frac{k_{l}}{2 \mu} \sqrt{\frac{r}{2 \pi}} \sin \theta / 2\left(k+1-2 \cos ^{2} \theta / 2\right)$

Similarly, for Mode $/$, displacements fields are given as:

$2 \mu u_{x}=k+1 \operatorname{Re} \phi-y \operatorname{lm} \phi^{\prime}$

$2 \mu u_{y}=k-1 / m \phi-y \operatorname{Re} \phi^{\prime}$

Simplifying Eqs. (73) and (74) further gives

$u_{x}=\frac{k_{l l}}{2 \mu} \sqrt{\frac{2}{2 \pi}} \sin \theta / 2\left(k+1+2 \cos ^{2} \theta / 2\right)$

$u_{y}=\frac{k_{l l}}{2 \mu} \sqrt{\frac{2}{2 \pi}} \cos \theta / 2\left(k-1-2 \sin ^{2} \theta / 2\right)$

Taking $\theta=\mp \pi$ and substituting into Eq. (72) yield:

$u_{y}=\frac{k+1}{2 \mu} k_{/} \sqrt{r / 2 \pi}$

$C T O D=2 u_{y}=\frac{k+1}{\mu} k_{/} \sqrt{r / 2 \pi}$

Setting $r=r_{\rho}$, then substituting Eq. (50) and (66) into (78) yield:

$C T O D=\frac{4}{\pi} \frac{k_{l}^{2}}{E \sigma_{y s}}=\frac{4 G}{\pi \sigma_{y s}} \quad$ Plane stress

Fig. 7 a Sharp crack tip. b Blunted crack tip 
CTOD $\frac{1}{\sqrt{3}} \frac{4\left(1-v^{2}\right)}{\pi} \frac{k_{l}^{2}}{E \sigma_{y s}} \quad$ Plane stress

Burdekin and Stone [42] further showed another method of computing crack tip opening displacement by adopting Dugdale plastic zone model approach (Fig. 6) and defining crack tip opening displacement at the end of the strip yield zone. From Eqs. (67) and (68) the vertical displacement is given as:

$u_{y}=\frac{1}{E}[2 \ln \bar{z}-y(1+v) R e z]$

$u_{y}=\frac{1}{E}\left[2\left(1-v^{2}\right) / m \bar{z}-y(1+v) R e z\right]$

Westergaard function is given as:

$z=\frac{\sigma z}{\sqrt{z^{2}-a_{1}^{2}}}$

Note that the stress function for pair of splitting forces $P$ is given as:

$z=\frac{2 P Z \sqrt{a_{1}^{2}-x^{2}}}{\pi \sqrt{z^{2}-a_{1}^{2}}\left(z^{2}-a_{1}^{2}\right)}$

By taking the integral of yield stress $\sigma_{y s}$ along the crack surface between $a$ and $a_{1}$ and substituting $P=-\sigma_{y s} d x$ into Eq. (84) result in:

$$
\begin{aligned}
z & =-\int_{a}^{a_{1}} \frac{2 P Z \sqrt{a_{1}^{2}-x^{2}}}{\pi \sqrt{z^{2}-a_{1}^{2}}\left(z^{2}-a_{1}^{2}\right)} \\
& =-\frac{2 \sigma_{y s}}{\pi}\left[\frac{z}{\sqrt{z^{2}-a_{1}^{2}}} \cos ^{-1}\left(\frac{a}{a_{1}}\right)-\cot ^{-1}\left(\frac{a}{z} \sqrt{\frac{z^{2}}{a_{1}^{2}}}-\frac{a_{1}^{2}}{a^{2}}\right)\right]
\end{aligned}
$$

Recall Eq. (61), $\frac{a}{a+\rho}=\cos \left(\frac{\pi \sigma}{\sigma_{y}}\right)=\frac{a}{a_{1}}=k$ and substituting Eq. (61) into Eq. (85) and superimposing Eq. (83) yielding:

$z=\frac{2 \sigma_{y s}}{\pi}\left[\frac{k}{\pi} \sqrt{\frac{z^{2}-a_{1}^{2}}{1-k^{2}}}\right]$

Integrating Eq. (86) further, gives:

$\bar{z}=\frac{2 \sigma_{y s}}{\pi}\left[z \omega_{1}-a \omega_{2}\right]$ where $\omega_{1}=\cot ^{-1} \sqrt{\frac{1-\left(a_{1}^{2} / a\right)^{2}}{1 / k^{2-1}}}$ and $\omega_{2}=\cot ^{-1} \sqrt{\frac{z^{2}-a_{1}^{2}}{1-k^{2}}}$.

On the crack plane, $y=0$, therefore Eq. (81) reduced to:

$u_{y}=\frac{2}{E} \operatorname{lm} \bar{z}$

Substituting Eq. (87) into (88) gives:

$u_{y}=\frac{4 \sigma_{y s}}{\pi E}\left[a \operatorname{coth}^{-1}\left(\frac{a_{1}^{2}-z^{2}}{1-k^{2}}\right)-z \operatorname{coth}^{-1}\left(\frac{k}{z} \sqrt{\frac{a_{1}^{2}-z^{2}}{1-k}}\right)\right]$

$|z| \leq a_{1}$, setting $z=a$, further reduced Eq. (89) to:

$\delta=2 u_{y}=\frac{8 \sigma_{y s} a}{\pi E} \ln \frac{1}{(k)}$

Substituting $k=\cos \frac{\pi \sigma}{\sigma_{y 5}}$ into Eq. (90) gives:

$C T O D=\frac{8 \sigma_{y s}}{\pi E} a \ln \sec \left(\frac{\pi}{2} \frac{\sigma}{\sigma_{y s}}\right)$

By adopting a series expansion of the term "Insec" gives:

$$
\begin{aligned}
\text { CTOD } & =\frac{8 \sigma_{y s} a}{\pi E}\left[\frac{1}{2}\left(\frac{\pi}{2} \frac{\sigma}{\sigma_{y s}}\right)^{2}+\frac{1}{12}\left(\frac{\pi}{2} \frac{\sigma}{\sigma_{y s}}\right)^{4}+\ldots\right] \\
& =\frac{K_{1}^{2}}{E \sigma_{y s}}\left[1+\frac{1}{6}\left(\frac{\pi}{2} \frac{\sigma}{\sigma_{y s}}\right)^{2}+\ldots\right]
\end{aligned}
$$

so, as $\frac{\sigma}{\sigma_{y s}} \rightarrow 0$

$C T O D=\frac{K_{1}^{2}}{E \sigma_{y s}}=\frac{G}{\sigma_{y s}} \quad$ Plane stress

Similarly, $C T O D=1 / 2\left(1-v^{2}\right) \frac{K_{1}^{2}}{E \sigma_{y s}} \quad$ Plane stress

\subsection{J-integral}

Cherepanov [43] and Rice [8] introduced J-integral theoretical concept to characterize condition of crack tip in twodimensional elastic plastic materials. The J-integral was formulated as path independent line integral around crack tip as shown in Fig. 8 and interpreted as rate of energy release.

$J=-\frac{d \Pi}{d A}=G=\frac{k_{1}^{2}}{E}$

where $A$ is crack area and $\pi$ is potential energy defined as: 


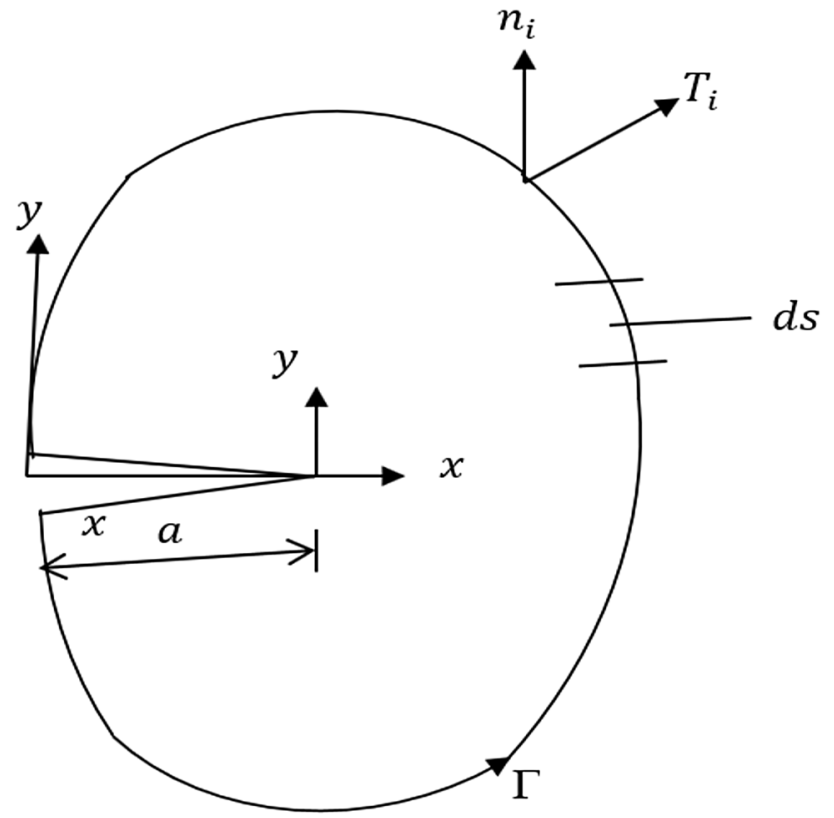

Fig. 8 Two-dimensional crack body

$\pi=\mathrm{U}-\mathrm{W}$

where $\mathrm{U}=$ external strained energy stored in the body and $W$ is the work done by external force. For a load control:

$\pi=\mathrm{U}-\mathrm{P} \Delta=-\mathrm{U}^{*}$

where $P$ is applied load and $U^{*}$ is strained energy per unit volume defined as:

$\mathrm{U}^{*}=\int_{0}^{\mathrm{p}} \Delta \mathrm{PdP}$

Hence, for a plate in load control,

$J=\left(\frac{\mathrm{dU}^{*}}{\mathrm{da}}\right)_{\mathrm{p}}=\left(\frac{\mathrm{d}}{\mathrm{da}} \int_{0}^{\mathrm{P}} \Delta \mathrm{dP}\right)_{\mathrm{p}}=\int_{0}^{\mathrm{P}}\left(\frac{\mathrm{d} \Delta}{\mathrm{da}}\right)_{\mathrm{p}} \mathrm{dP}$

where the crack advances at a fixed displacement, $\mathrm{W}=0$ and $J$ is given by:

$J=-\left(\frac{\mathrm{dU}^{*}}{\mathrm{da}}\right)_{\Delta}=-\left(\frac{\mathrm{d}}{\mathrm{da}} \int_{0}^{\Delta} \mathrm{Pd} \Delta\right)_{\Delta}=\int_{0}^{\mathrm{P}}\left(\frac{\mathrm{d} \Delta}{\mathrm{da}}\right)_{\mathrm{p}} \mathrm{dP}$

The potential energy $\pi$ of two-dimensional body of area, $A$, with surface traction, $T_{i}$ prescribed over a portion of the boundary surface, $\Gamma$ given as:
$\pi=\int_{A} W d A-\int_{\Gamma} T_{i} u_{i} d s$

Differentiating Eq. (101) with respect to crack length $a$ yields:

$\frac{d \pi}{d a}=\int_{A} \frac{d W}{d a} d A-\int_{\Gamma} T_{i} \frac{d u_{i}}{d a} d s$

Considering Fig. 8,

$\frac{\partial}{d a}=\frac{\partial}{d a}-\frac{\partial}{d x}$

Substituting Eq. (103) into Eq. (102) yield:

$\frac{d \pi}{d a}=\int_{A}\left(\frac{\partial W}{\partial a}-\frac{\partial W}{\partial x}\right) d A-\int_{\Gamma} T_{i}\left(\frac{\partial u_{i}}{\partial a}-\frac{\partial u_{i}}{\partial x}\right) d s$

where $\frac{\partial W}{\partial a}=\frac{\partial W}{\partial \varepsilon_{i j}} \frac{\partial \varepsilon_{i j}}{\partial a}=\sigma_{i j} \frac{\partial \varepsilon_{i j}}{\partial a}$.

Applying principle of virtual work yield:

$\int_{A} \frac{\partial W}{d a} d A=\int_{A} \sigma_{i j} \frac{\partial \varepsilon_{i j}}{\partial a} d A=\int_{\Gamma} T_{i} \frac{\partial u_{i}}{\partial a} d s$

Application of divergence theorem yield:

$\int_{A} \frac{\partial W}{\partial x} d A=\int_{\Gamma} W d y$

Substituting Eqs. (105) and (106) into Eq. (104) gives:

$J=-\frac{d \pi}{d a}=\int_{\Gamma} W d y-T_{i} \frac{\partial u_{i}}{\partial x} d s$

\section{Fracture mechanics application to fatigue}

Fatigue is understood as a progressive failure in material components due to repeated stresses and strains variation while the fatigue life is the time it takes for the progressive failure to develop a through wall defect $[44,45]$. But the fatigue crack propagation is defined by Correia et al. [46] as continuous crack initialization process that may lead to failure of representative elementary material. Several fatigue life prediction models have been developed for the computation of fatigue growth and remaining life of materials or structural components. The fatigue life prediction models are based on three methodologies namely stress-life, strain-life and fracture mechanics [47]. In fracture mechanics-based prediction models, the stress intensity factor parameter is more widely used in the fatigue life 
prediction than the CTOD and the J-integral [48]. Nonetheless, recent works relate fracture mechanics-based parameters with strain life prediction models.

\subsection{Fatigue growth based in fracture mechanics}

Paris [49] was the first to conceive the fatigue crack growth rate by idealizing stress intensity factor range. The mathematical relationship between crack growth per cycle $(d a / d N)$ and the stress intensity factor range $(\Delta k)$ was formulated by Paris and Erdogan [50]:

$\frac{d a}{d N}=C_{k}(\Delta k)^{m_{k}}$

where $d a=$ incremental crack length; $d N=$ incremental number of cycles; $C_{k}, m_{k}=$ Paris empirical parameters based on stress intensity factor that are determined from curve fit to test data. The applied stress intensity factor range $(\Delta k)$ is defined as:

$\Delta k=k_{\max }-k_{\min }$

where $k_{\max }$ and $k_{\min }$ are maximum applied stress intensity factor and minimum applied stress intensity factor respectively.

A fatigue rate curve (Fig. 9) of the crack increment per load $(d a / d N)$ versus the stress intensity factor range $(\Delta \mathrm{K})$ has three divisions, refers to region as I, II and III. The fatigue rate curve (Fig. 9) and the Eq. (108) have several limitations such as application to only small-scale yielding, rate curve dependency on fitting parameters and stress ratio [51]. Other limitations of the Paris law include the inability to be applied to crack near threshold, near unstable crack propagation regimes, variable amplitude loadings and crack closure effect [52].

Elber [53] raised concern of crack closure existence on fatigue specimens during minimum tensile load and effect

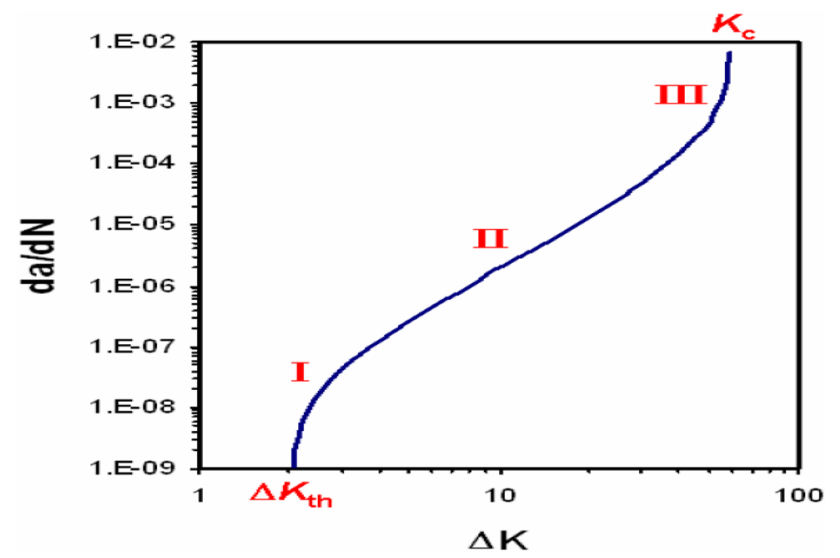

on the fatigue crack propagation. Crack closure reduces fatigue crack growth rate by decreasing effective stress intensity factor range. Elber $[53,54]$ proposed modification to Eq. (108) to account for effect of stress ratio and the crack closure effect on fatigue crack propagation by replacing the applied stress intensity factor range $(\Delta k)$ with the effective applied stress intensity factor $\left(\Delta k_{\text {eff }}\right)$ as:

$\frac{d a}{d N}=C_{k}\left(\Delta k_{e f f}\right)^{m_{k}}$

Effective applied stress intensity factor range $\left(\Delta k_{\text {eff }}\right)$ is defined as:

$\left(\Delta k_{e f f}\right)=k_{\max }-k_{o p}$

where $k_{o p}=$ crack opening stress intensity factor.

Walker [55] modified the Paris Eq. (108) by introducing a fatigue crack growth equation exponent, $\gamma$ to account for effect of stress ratio, $R$ on the fatigue crack propagation and equating $R=0$. The Walker's model is given as:

$\frac{d a}{d N}=C_{k}\left[\frac{\Delta K}{(1-R)^{1-\gamma}}\right]^{m_{k}}$

The Walker model of Eq. (112) did not consider the near unstable crack propagation regime when the stress intensity factor approaches critical value. Therefore, Foreman [56] proposed a model by modifying Eq. (112) to describe the near unstable propagation in the region III of fatigue curve rate (Fig. 9). The Foreman model is represented as:

$\frac{d a}{d N}=\left[\frac{C_{k}(\Delta k)^{m_{k}}}{(1-R)\left(k_{c}-k_{\max }\right)}\right]$

where $k_{c}=$ critical fracture toughness of material.

Collipriest [57], Priddle [58] and McEvily [59] proposed crack growth models capable of describing all three regions $(I, I I, I I)$ of the fatigue rate curve. The Collipriest, Priddle and McEvily models are given in Eqs. (114), (115) and (116) respectively:

$\frac{d a}{d N}=C_{k}\left(k_{c} \Delta k\right)^{m_{k} / 2} \operatorname{Exp}\left[\ln \left(\frac{K_{c}}{\Delta K_{t h}}\right)^{m_{k} / 2} \tanh ^{-1}\left\{\frac{\ln \left[\frac{\Delta k^{2}}{(1-R) k_{c} \Delta k_{t h}}\right]}{\ln \left[\frac{(1-R) k_{c}}{\Delta k_{t h}}\right]}\right\}\right]$

$\frac{d a}{d N}=C_{k}\left(\frac{\Delta k-\Delta k_{t h}}{k_{c}-k_{\max }}\right)^{m_{k}}$

$\frac{d a}{d N}=C_{k}\left(\Delta k-\Delta k_{t h}\right)^{2}\left(1+\frac{\Delta k}{k_{c}-k}\right)$

Fig. 9 Typical fatigue crack growth rate curve 
where $\Delta k_{t h}=$ Propagation threshold. But Weertman [60] proposed fatigue crack growth that can describe region III of the fatigue rate curve. The Weertman proposed model is given as:

$\frac{d a}{d N}=\frac{C_{k}(\Delta k)^{4}}{k_{c}^{2}-k_{\max }^{2}}$

\subsection{Fatigue crack propagation under large scale plasticity}

Dowling [61, 62], Dowling and Begley [63] were the first to successfully correlate the fatigue crack growth rate with the J-integral fracture mechanics parameter through series of experimental data to account for large scale plasticity effect. The mathematical correlation between the fatigue crack growth rate and the J-integral range $(\Delta J)$ is given as:

$\frac{d a}{d N}=C_{J}(\Delta J)^{m_{J}}$

The $J$-integral range $(\Delta J)$ is defined as:

$\Delta J=\frac{\eta}{B b} \int_{V_{\min }}^{V_{\max }}\left(P_{\max }-P_{\min }\right) d V$

where $B=$ specimen thickness; $b=$ uncracked ligament length; $\eta=$ constant for deeply notched $(=2) ; d V=$ change in load displacement; $C_{\jmath}, m_{J}=$ Paris empirical parameters based on J-integral that are determined from curve fit to test data, $V_{\max }$ and $V_{\text {min }}$ are maximum and minimum load line displacement respectively.

Analytical analysis by Tanaka [64] further suggested adoption of the $J$-integral parameter as criteria for the fatigue crack growth rate since cyclic J-integral for large scale is depended on loading process. Results of recent investigations for a fatigue crack propagation under a large scale plasticity with the elastic-plastic fracture mechanics parameter by Azmi et al. [65], Vormwald [66] and Kuai et al. [67] agreed with previous studies that the $J$-integral parameter could be used to characterize the fatigue crack growth rate. But, Laird and Smith [68] were the first to argue possible relationship between fatigue growth mechanisms and crack tip blunting following examination of some fracture surfaces of ductile metals under cyclic stresses. Kikukawa et al. [69], Newmann [70] and Tomkins [71] attempted to relate the crack tip opening displacement (CTOD) parameter with the fatigue crack growth rate from direct microscopic examination of fatigue crack growth mechanisms. Recent numerical studies by Antunes et al. [51] and Antunes et al. [72] on the fatigue crack growth rate correlation with the crack tip opening displacement range $(\triangle C T O D)$ indicated increasing crack lengths with increasing $\triangle C T O D$ and corresponding fatigue growths. Similarly, an experimental study by Vasco-Olmo [73] agreed with previous studies that the $\triangle C T O D$ could replace the $\Delta k$ in characterization of the fatigue crack propagation because the CTOD considers crack shielding and fatigue threshold. Tanaka et al. [74] correlated the crack tip opening displacement parameter with the fatigue crack growth rate through experimental investigation of crack opening behavior and fractoragraph. The mathematical correlation between the fatigue crack growth rate and the CTOD is given as:

$\frac{d a}{d N}=C_{\delta}(\Delta C T O D)^{m_{\delta}}$

where $\triangle C T O D$ is represented in the form:

$\Delta C T O D=B\left[\frac{\Delta J}{\sigma_{\gamma s}}\right]^{q}$

where $C_{\delta}, m_{\delta}=$ Paris empirical parameters based on CTOD that are determined from curve fit to test data, $\sigma_{\gamma s}=$ yield strength and $q=$ material constant. The values of $q$ is generally greater than 1 but equal to 1 when geometrical shapes of the crack tip opening are identical.

\subsection{Fatigue growth based on local strain approach}

According to Hafezi et al. [75], stress-strain fields at a crack tip vicinity can be calculated using a combination of elastic-plastic analysis and fatigue damage law to predict failure of elementary material representative with either the stress life or the strain-life approach (local strain based). The stress-life approach in fatigue life prediction of representative elementary material is usually used at the designed stage of structures and employed when nominal elastic stresses and strains are present. But the local strainbased approach is preferred if the elementary material is subjected to nominally cyclic elastic stresses and strains with stress concentration that may lead to local cyclic plasticity, thus it is used in fatigue life prediction of crack initiation on notched component of materials $[47,76]$. The local strain-based approach considers stresses and strains at the crack tip and associated stress intensity factor to compute total fatigue life of both crack initiation and propagation $[77,78]$. Several models have been proposed to replace the fatigue life prediction in the last 4 decades. Among the famous models were Coffin [79] and Manson [80] that proposed to replace the fracture mechanics-based fatigue crack growth model with the local strain-based approach. The Coffin-Manson [79, 80] model for computing a material failure relationship is given as: 
$\frac{\Delta \varepsilon}{2}=\frac{\sigma_{f}^{\prime}}{2}\left(2 N_{f}\right)^{d}+\varepsilon_{f}^{\prime}\left(2 N_{f}\right)^{c}$

where $\Delta \mathcal{E}=$ strain range; $\sigma_{f}^{\prime}=$ fatigue strength coefficient; $\varepsilon_{f}^{l}=$ fatigue ductility coefficient; $N_{f}=$ number of cycles required for representative material to fail; $d=$ fatigue strength exponent and $c=$ fatigue ductility exponent.

Morrow [81] proposed another local strain-based approach for computing fatigue life of a material by modifying Coffin-Manson's Eq. (122) to account for mean stress, $\sigma_{m}$ effect on fatigue life. The Morrow local strain-based model is given in the form:

$\frac{\Delta \varepsilon}{2}=\frac{\sigma_{f}^{l}-\sigma_{m}}{E}\left(2 N_{f}\right)^{d}+\varepsilon_{f}^{l}\left(2 N_{f}\right)^{c}$

Similar, the local strain-based model for fatigue damage parameter was proposed by Smith-Watson-Topper [82] to account for maximum stress and stress ratio effect. The Smith-Watson-Topper [82] model is represented in the form:

$\sigma_{\max }\left(\frac{\Delta \varepsilon}{2}\right)=\frac{\left(\sigma_{f}^{\prime}\right)^{2}\left(2 N_{f}\right)^{2 d}}{E}+\sigma_{f}^{\prime} \varepsilon_{f}^{\prime}\left(2 N_{f}\right)^{d+c}$

Noroozi et al. [83-85] recently derived a mathematical relationship between the fracture fatigue crack growth and the local strain-based approach for fatigue growth prediction. The Noroozi et al. [84, 85] model suggested using strainlife approach with either Smith-Watson-Topper's Eq. (124) or Morrow's Eq. (123) and considers the residual stress and the stress ratio effect on fatigue life prediction. The model is developed to compute the elastoplastic stresses and strains at the elementary material blocks ahead of the crack tip (Fig. 10) and represented in the form:

$\frac{d a}{d N}=\frac{\rho^{*}}{N_{f}}$

where $\rho^{*}=$ elementary material block size while the $\frac{d a}{d N}$ is defined as follow:

$\frac{d a}{d N}=C_{k}\left[\left(k_{\text {max }, t o t}\right)^{\gamma}\left(\Delta k_{\text {tot }}\right)^{m_{k}}\right]^{\gamma}$

where $k_{\text {max,tot }}=$ maximum total stress intensity factor; $\Delta k_{\text {tot }}=$ total stress intensity factor range. The $k_{\text {max,tot }}$ and $\Delta k_{\text {tot }}$ are defined further in Eq. (127) and (128) respectively:

$k_{\text {max }, \text { tot }}=k_{\text {max }}+k_{r}$

$\Delta k_{\text {tot }}=\Delta k+k_{r}$

where $k_{r}=$ residual stress intensity factor.

Huffman [86] recently derived another mathematical relation between the fatigue crack growth and the local strain approach using strain energy densities from applied loads and the strain energy of dislocations to compute the strainlife, stress-life and fatigue crack growth rate. Huffman [86] fatigue crack growth rate based on a strain energy density model is given in the form:

$\frac{d a}{d N}=\left(\frac{\Delta a}{U_{d}^{2} \rho_{c}^{2}}\right)\left(\frac{n^{\prime}}{1+n^{\prime}}\right)\left(\frac{1}{K^{\prime}}\right)\left(\sigma_{\max }^{2}\right)\left(\sigma_{a}\right)^{1+\frac{n^{\prime}}{n^{\prime}}}$

where $U_{d}=$ dislocation strain energy; $\rho_{c}=$ critical dislocation density; $K^{\prime}=$ cyclic strength coefficient; $n^{\prime}=$ cyclic

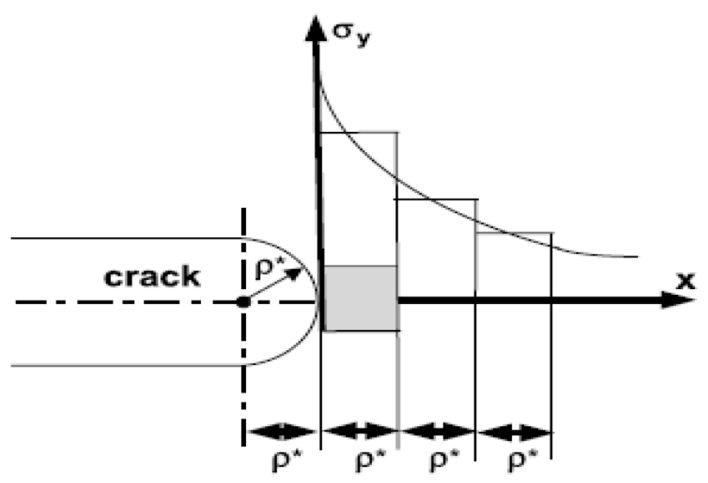

(a)

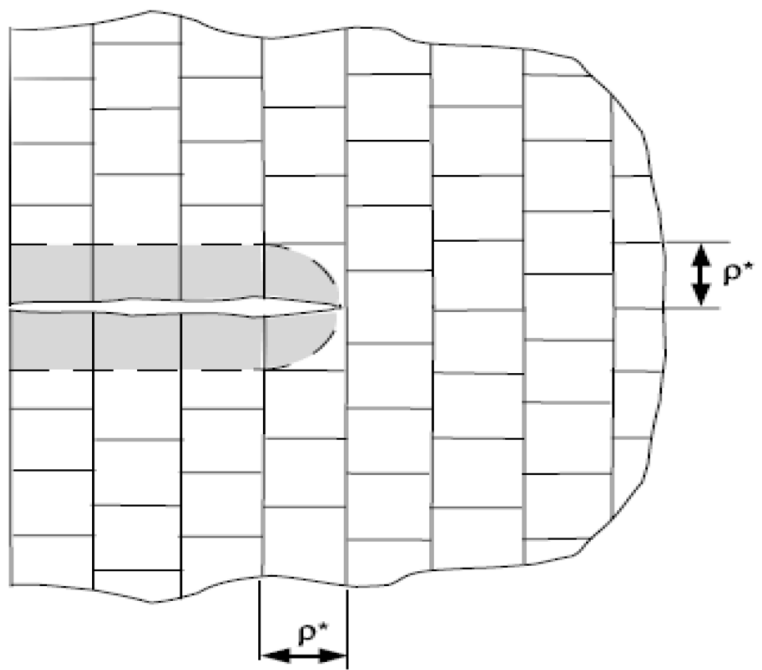

(b)

Fig. 10 Crack configuration of Unigrow model: a Crack tip and average stresses over individual elementary material blocks at the tensile maximum and compressive minimum load; $\mathbf{b}$ crack and elementary material blocks [83] 
strain hardening exponent, $\sigma_{a}==$ applied stress; $\Delta a=$ crack length range.

\subsection{Probabilistic models of local strain approach}

The local strain-based fatigue life prediction models by Coffin-Manson and Smith-Watson-Topper (SWT) are deterministic methods [46]. Thus, Castillo and FernándezCanteli [87] proposed probabilistic fatigue life models for stress and strain-based fatigue damage using Weibull distribution. Castillo and Fernandez-Canteli [87] formulated probabilistic strain life $\left(\mathbb{P}-\varepsilon_{a}-N\right)$ model by assuming variables, represented as:

$\mathbb{P}=f\left(N_{f}^{*} ; \varepsilon_{a}^{*}\right)=1-\exp \left\{-\left[\frac{\log \left(N_{f} / N_{o}\right) \log \left(\varepsilon_{a} / \varepsilon_{a o}\right)-\lambda}{\delta}\right]^{\beta}\right\}$ $\log \left(N_{f} / N_{o}\right) \log \left(\varepsilon_{a} / \varepsilon_{a o}\right) \geq \lambda$

where $\mathbb{P}=$ probability of failure; $N_{o}$ and $\varepsilon_{a o}=$ normalilizing values; $\lambda, \delta$ and $\beta=$ non-dimensional Weibull model parameters. Their physical meanings shown in Fig. 11 are

$N_{o}=$ threshold value of lifetime; $\varepsilon_{a o}=$ endurance limit of $\varepsilon_{a} ; \lambda=$ parameter defining the position of the corresponding zero-percentile curve; $\delta=$ scale parameter and $\beta=$ shape parameter. The probability depends solely on the product of $N_{f}^{*} \varepsilon_{a}^{*}$, defined as $N_{f}^{*}=$ dimensionless life $\left(=\log \left(N_{f} / N_{o}\right)\right)$ and $\varepsilon_{a}^{*}=$ dimensionless strain amplitude $\left(=\log \left(\varepsilon_{a} / \varepsilon_{a 0}\right)\right)$. Thus,

$N_{f}^{*} \varepsilon_{a}^{*} \sim w(\lambda, \delta, \beta) \Leftrightarrow N_{f}^{*} \sim w\left(\frac{\lambda}{\varepsilon_{a}}, \frac{\delta}{\varepsilon_{a}}, \beta\right)$

Furthermore, strain life and Smith-Watson-Topper (SWT) deterministic models have shown identical characteristics in fatigue damage analysis $[46,88]$. Therefore, probabilistic fatigue life model of $\mathbb{P}-\varepsilon_{a}-N$ field developed by Castillo and Fernández-Cansteli [87] had been extended to develop probabilistic Smith-Watson-Topper life $(\mathbb{P}-S W T-N)$ model, and is given as: that the fatigue life and total strain amplitude are random defined as:

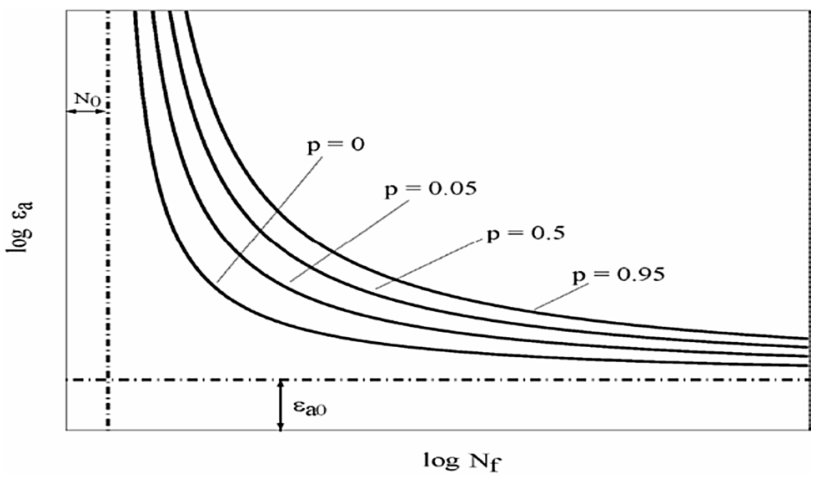

Fig. 11 Percentile curve between dimensionless lifetime $\left(N_{f}^{*}\right)$ and strain amplitude $\left(\varepsilon_{a}^{*}\right)$ for $\mathbb{P}-\varepsilon_{a}-N$ field

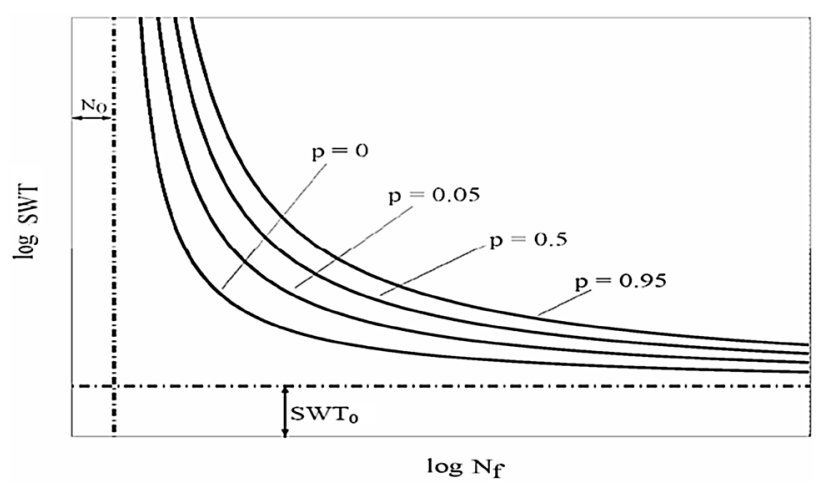

Fig. 12 Percentile curve between dimensionless lifetime $\left(N_{f}^{*}\right)$ and damage parameter $\left(S W T^{*}\right)$ for $\mathbb{P}-S W T-N$ field

in Fig. 12. Similarly, the probability depends solely on the product of $N_{f}^{*} S W T^{*}$ and $S W T^{*}=$ damage parameter $\left(=\log \left(S W T / S W T_{0}\right)\right)$. Thus,

$N_{f}^{*} S W T^{*} \sim w(\lambda, \delta, \beta) \Leftrightarrow N_{f}^{*} \sim w\left(\frac{\lambda}{S W T^{*}}, \frac{\delta}{S W T^{*}}, \beta\right)$

\section{Conclusions}

$\mathbb{P}=f\left(N_{f}^{*} ; S W T^{*}\right)=1-\exp \left\{-\left[\frac{\log \left(N_{f} / N_{o}\right) \log \left(S W T / S W T_{o}\right)-\lambda}{\delta}\right]^{\beta}\right\}$ where $S W T_{o}=$ normalilizing value, but $S W T_{o}=$ fatigue limit of $S W T$ for physical meaning parameter. The physical meaning parameters of Eq. (132) parameters are shown
This paper presents a review of mathematical derivation of stress concentration, fracture stress, stress intensity factor, crack tip opening displacement and J-integral from 
the first principle. The linear elastic parameter shows the stress field tends to zero as the tip of crack approaches zero, thus it is only applicable to brittle materials. But the elastic plastic parameters show the stress field solutions are not equal to zero at both the blunted and sharp crack tips, thus applicable to ductile materials. The paper considers further the fatigue life correlation with J-integral, crack tip opening displacement and local strain-based approach methods. The prediction of fatigue crack growth rate with the J-integral and the crack tip opening displacement parameters considers the plasticity, crack shielding and fatigue threshold effect. On the other hand, the fatigue life prediction of crack initiation and propagation of notched specimens with the local strain-based approach considers maximum stress and residual stress intensity factor, thus has several benefits over the fatigue life prediction with conventional stress intensity factor.

\section{Compliance with ethical standards}

Conflict of interest The author declares that he has no conflict of interest.

\section{References}

1. Anderson TL (2005) Fracture mechanics-fundamental and application, 3rd edn. CRC Press Publisher, Boca Raton

2. Griffith AA (1920) The phenomena of rupture and flow in solid. Philos Trans 221:163-198

3. Irwin GR (1957) Analysis of stresses and strains near the end of a crack traversing a plate. J Appl Mech 24:361-364

4. Orowan E (1949) Fracture and strength of solids. Rep Prog Phys 12(1):185-232

5. Irwin GR (1948) Dynamic of fracture: in fracturing of metals. In: ASM symposium, Cleveland, pp 147-166

6. Irwin GR (1960) Structural mechanics. In: Proceedings of the first symposium on Naval structural mechanics. Pergamon Press, New York, pp 557-591.

7. Wells AA (1961) Unstable crack propagation in metals: cleavage and fast. In: Crack propagation symposium proceeding, p 84

8. Rice JR (1968) A path independent integral and the approximate analysis of strain concentration by notches and cracks. J Appl Mech 35:376-386

9. Newman JC (1971) An improved method of collocation for the stress analysis of cracked plates with various shaped boundaries. NASA technical notes, Washington, DC

10. Ameh ES, Onyekpe BO (2016) Effect of high strength steel microstructure on cracks tip opening displacement. Am J Eng Res 5:72-78

11. Vukelic G, Brinc J (2011) J-integral as possible criterion in material fracture toughness assessment. Eng Rev 2:91-96

12. Gopichand A, Srinivas Y, Sharma AVL (2012) Computation of stress intensity factor of brass plate with edge crack using J-integral technique. Int J Res Eng Technol 10:2319-1163

13. McDowell DL (1996) Basic issue in the mechanics of high cycle metal fatigue. Int J Fract 80:103-145

14. Cowles BA (1996) High cycle fatigue in aircraft gas turbine-an industry perspective. Int J Fract 80:147-163
15. Dirik H, Yalcinkaya T (2016) Fatigue crack growth under variable amplitude loading through XFEM. Procedia Struct Integr 2:3073-3080

16. Chhibber R, Arora N, Gupta SR, Dutta BK (2006) Use of bimetallic welds in nuclear reactors: associated problems and structural integrity assessment issues. J Mech Eng Sci 220:1121-1133

17. Zhu X (2013) Fracture toughness testing, evaluation and standardization. J Pipeline Eng 12(3):145-155

18. Veeranjaneyulu J, Rao RH (2012) Simulation of the crack propagation using fracture mechanics techniques in aero structure. Int J Eng Res Appl 2(5):1168-1173

19. Pwei $R$ (2010) Fracture mechanics, integration of mechanics material science and chemistry. Cambridge Press University, Cambridge

20. Zhu X, Joyce JA (2012) A review of fracture toughness (g, k, ctod, ctoa), testing and standardization. Eng Fract Mech 85:1-46

21. Erdogan F (2000) Fracture mechanics. Int J Solids Struct 13:171-218

22. Cottrell B (2002) The past, present and future of fracture mechanics. Eng Fract Mech 69:533-565

23. Shinde SS, Dhamejani CL (2015) Literature review of fracture toughness and impact toughness. Int J Innov Eng Technol 2(2):1-5

24. Elices M, Guinea GV, Gomez J, Planas J (2002) The cohesive zone model: advantages, limitations and challenges. Eng Fract Mech 69:137-163

25. Kumar A, Murthy ARC, Lyer NR A study of the stress ratio effects on fatigue crack growth using lowess regression. In: Proceeding of the international conference on advances in civil structural and mechanical, India, pp 47-51

26. Beden SM, Abdullah S, Ariffin AK (2009) Review of fatigue crack propagation models for metallic components. Eur J Sci Res 28:364-397

27. Pegoretti A, Bertoldi E, Ricco T (2005) Plane stress fracture toughness of ductile polymeric films: effect of strain rate on the essential work of fracture parameter. In: 11th international conference on fracture, Italy, pp 20-25

28. Broek D (1974) Elementary engineering fracture mechanics. Kluwer Academic, New York

29. Inglis CE (1913) Stresses in a plate due to the presence of cracks and sharp corner. Trans Inst Naval Archit 55:219-241

30. Neuber H (1937) Translation: theory of notched stresses. Julius Springer, Berlin

31. Durelli AJ, Murray WM (1943) Stress distribution around an elliptical discontinuity in any two-dimensional, uniform and axial system of combined stress. Exp Stress Anal 1:384-409

32. Timoshenko S, Goodier JN (1951) Theory of elasticity, 2nd edn. Mc Graw-Hill, New York

33. Rossmanith HP (1995) An introduction to K. Wieghardt's historical paper on splitting and cracking and cracking of elastic bodies. Fatigue Fract Eng Mater Struct 12:1367-1369

34. Westergaard HM (1939) Computation of stress analysis. In Proceeding of the $7^{\text {th }}$ annual research council, pp 120-14

35. Muskhelishvili NI (1943) Some basic problems in the mathematical theory of elasticity. Noord-Hoff, Groningen

36. Irwin GR (1956) Onset of fast crack propagation in high strength steel and aluminum alloys. In: Research conference proceeding in sagamore, vol 2, pp 289-305

37. Janssen M, Zuidema J, Wanhill RJH (2001) Fracture mechanics, 2nd edn. VSSD, Delft

38. McClintock FA, Irwin GR (1965) Plastic aspect of fracture mechanics. Am Soc Test Mater ASTM STP 381:84-113

39. Irwin GR (1961) Plastic zone near a crack and fracture toughness. Res Conf Proc Sagamore 4:63-78

40. Dugdale DS (1960) Yielding in steel sheets containing slits. J Mech Phys Solids 8:100-110 
41. Barenblatt GI (1962) Mathematical theory of equilibrium crack in brittle fracture. J Adv Appl Mech 7:55-129

42. Burdekin FM, Stone DEW (1966) The crack opening displacement approach to fracture mechanics in yielding materials. J Strain Anal 1:145-153

43. Cherepanov GP (1967) The propagation of cracks in a continuous medium. J Appl Math Mech 31(3):476-488

44. Ritchie RO (1988) Mechanism of crack tip deformation and extension fatigue. Fatigue Crack Propag ASTM STP 415:241-242

45. Panda CS (2012) Fundamentals of fatigue crack initiation and propagation. Material Science and Technical Division NAVA Research Laboratory, Washington, DC

46. Correia JAFO, DeJesus AMP, Fernández-Canteli A, Calçada RAB (2015) Modeling probabilistic fatigue crack propagation rates for mild steel structural steel. Fracttura ed integrità structurale 31:80-96

47. Rahman MM, Kadirgama K, Noor MM, Rehab MRM, Kesulai SA (2009) Fatigue life prediction of lower suspension arm using strain-life approach. Eur J Sci Res 30:437-450

48. Ritchie RO, Suresh S (1982) The fracture mechanics similitude concept: questions concerning its application to the behaviour of short fatigue crack. Mater Sci Eng 57:L27-L30

49. Paris PC (1960) A critical analysis of crack propagation law. J Basic Eng 85:528-534

50. Paris PC, Erdogan FA (1963) A critical analysis of crack propagation laws, transaction ASME. J Basic Eng D85:528-534

51. Antunes FV, Branco R, Prates P, Costa JDM (2019) Fatigue crack growth in notched specimens: a numerical analysis. Fracttura ed integrità structurale 48:666-675

52. Correia JAFO, DeJesus AMP, Fernández-Canteli A (2013) Local unified model for fatigue crack initiation and propagation: application to notched geometry. Eng Struct 52:80-96

53. Elber W (1970) Fatigue crack closure under cyclic tension. Eng Fract Mech 2:37-45

54. Elber W (1971) The significance of fatigue closure in: damage tolerance. American Society for Testing and Materials (ASTM), West Conshohocken, pp 230-242

55. Walker EK (1970) The effect of stress ratio during crack propagation and fatigue for 2024-T3 and 7076-T6 aluminumin: effect of environment and complex loading history on fatigue life. ASTM STP 462:1-14

56. Forman RG (1972) Study of fatigue crack initiation from flaws using fracture mechanics theory. Eng Fract Mech 4:333-345

57. Collipriest JE (1972) An experimentalist view of the surface flaw problems: physical problems and computation solution. ASME, New York, pp 43-62

58. Priddle EK (1972) Constant amplitude fatigue crack propagation in mild steel at low stress intensity: the effect of mean stress on propagation rate. Technical report on nuclear laboratory, central electricity generator boards (1972), RD/B/N2233 Berkley

59. McEvily AJ (1974) Phenomenological and microstructural aspect of fatigue. In: International conference on the strength of metal and alloy, Cambridge, UK, pp 204-213

60. Weertman J (1966) Rate of growth of fatigue cracks calculated from the theory of infinitesimal dislocations distributed on a crack plane. Int J Fract 2:460-467

61. Dowling NE (1976) Geometry effects and J-integral application to elastic-plastic fatigue crack growth. Cracks Fract ASTMI STP 603:19-32
62. Dowling NE (1977) In cyclic stress-strain and plastic deformation aspect of fatigue crack growth. ASTM Specif Technol 637:p97

63. Dowling NE, Begley JA (1976) Mechanics of crack growth. ASTM STP 590:812-1013

64. Tanaka K (1983) The cyclic J-integral as a criterion for fatigue crack growth. Int J Fract 22:91-104

65. Azmi MSM, Fujii T, Tosho K, Shimamu Y (2017) On the $\Delta$ J-integral to characterize elastic-plastic fatigue crack growth. Eng Fract Mech 176:300-311

66. Vormwald M (2014) Fatigue crack propagation under large cyclic plastic strain conditions. Procedia Mater Sci 3:301-306

67. Kuai H, Lee HJ, Zi G, Mun S (2009) Application of generalized J-integral to crack propagation modeling of asphalt concrete under repeated loading. Transp Res Board Natl Acad 2127:72-81

68. Laird C, Smith GC (1962) Crack propagation in high stress fatigue. Philos Mag 7:847-852

69. Kikukawa M, Jono M, Adachi M (1979) Direct observation and mechanism of fatigue crack propagation. Am Soc Test Mater STP 675:234-253

70. Newmann P (1974) New experiments concerning the slip processes at propagating fatigue crack. Acta Metal 22:1155-1165

71. Tomkins B (1980) Micromechanism of fatigue crack growth at high stress. Mater Sci 14:408-417

72. Antunes FV, Rodriguez SM, Branco R, Camas D (2016) A numerical analysis of CTOD in constant amplitude fatigue crack growth. Theor Appl Fract Mech 85(A):45-55

73. Vasco-Olmo JM, Diaz FA, Antunes FV, James MN (2017) Experimental evaluation of CTOD in constant amplitude fatigue crack growth from crack tip displacement fields. Fracttura integrità structurale 41:157-165

74. Tanaka K, Hoshide T, Sakai N (1984) Mechanics of fatigue crack propagation by crack tip plastic blunting. Eng Fract Mech 19:805-825

75. Hafezi MH, Abdullah NN, Correia JFO, DeJesus AMP (2012) An assessment of a strain life approach for fatigue crack growth. Int J Struct Integr 3:344-376

76. Shang DG, Wang DK, Li M, Yao WX (2001) Local stress-strain field intensity approach to fatigue life prediction under random cyclic loading. Int J Fatigue 23:903-910

77. Hurley RJ, Evans WJ (2007) A methodology for predicting fatigue crack propagation rate in titanium-based damage accumulation. Sci Mater 56:681-684

78. Huffman PJ, Ferreira J, Corria JAFO, DeJesus AMP, Lesiuk G, Berto F, Fernández-Canteli A, Glinka G (2017) Fatigue crack propagation prediction of a pressure vessel mild steel based on a strain energy density model. Frattura ed integrità structurale 42:74-84

79. Coffin LF (1954) A study of the effects of the cyclic thermal stresses on a ductile metal. Transl ASME 76:931-950

80. Manson SS Behavior of materials under conditions of thermal stress, National advisory committee for aeronautics. Report No. NACA TN-2933, Washington DC

81. Morrow JD (1965) Cyclic plastic strain energy and fatigue of metals. Int Frict Damping Cyclic Plast ASTM STP 378:45-87

82. Smith KN, Watson P, Topper TH (1970) A stress-strain function for the fatigue metals. J Mater 5:767-778

83. Noroozi AH, Glinka G, Lambert S (2005) A two parameter driving force for fatigue crack growth analysis. Int J Fatigue 27:1277-1296 
84. Noroozi AH, Glinka G, Lambert S (2007) A study of the stress ratio effects on fatigue crack growth driving force. Int J Fatigue 29:1616-1633

85. Noroozi AH, Glinka G, Lambert S (2008) Prediction of fatigue crack growth under constant amplitude loading and a single overload based on elastic-plastic crack tip stresses and strains. Eng Fract Mech 75:188-206

86. Huffman PJ (2016) A strain energy-based damage model for fatigue crack initiation and growth. Int J Fatigue 88:197-204

87. Castillo E, Fernández-Canteli A (2009) A unified statistical methodology for modelling fatigue damage. Springer, Berlin
88. Correia JAFO, Huffman PJ, DeJesus AMP, Lesiuk G, Castro JM, Calçada RAB, Berto F (2018) Probabilistic fatigue crack initiation and propagation fields using the strain energy density. Strength Mater 50:620-635

Publisher's Note Springer Nature remains neutral with regard to jurisdictional claims in published maps and institutional affiliations. 